INTERNATIONAL

FOOD POLICY

RESEARCH

INSTITUTE

IFPRI

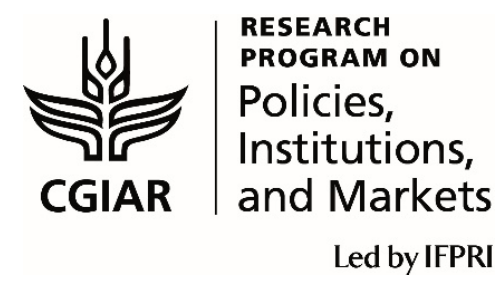

IFPRI Discussion Paper 01984

December 2020

\title{
Measurement of Intra-household Resource Control \\ Exploring the Validity of Experimental Measures
}

\author{
Kate Ambler \\ Kelly Jones \\ Maria P. Recalde
}

Markets, Trade, and Institutions Division 


\section{INTERNATIONAL FOOD POLICY RESEARCH INSTITUTE}

The International Food Policy Research Institute (IFPRI), a CGIAR Research Center established in 1975, provides research-based policy solutions to sustainably reduce poverty and end hunger and malnutrition. IFPRI's strategic research aims to foster a climate-resilient and sustainable food supply; promote healthy diets and nutrition for all; build inclusive and efficient markets, trade systems, and food industries; transform agricultural and rural economies; and strengthen institutions and governance. Gender is integrated in all the Institute's work. Partnerships, communications, capacity strengthening, and data and knowledge management are essential components to translate IFPRI's research from action to impact. The Institute's regional and country programs play a critical role in responding to demand for food policy research and in delivering holistic support for country-led development. IFPRI collaborates with partners around the world.

\section{AUTHORS}

Kate Ambler (k.ambler@cgiar.org) is a Research Fellow in the Markets, Trade, and Institutions Division of the International Food Policy Research Institute (IFPRI), Washington, D.C.

Kelly Jones (kmjones@american.edu) is an Assistant Professor of Economics at the American University, Washington, D.C.

Maria P. Recalde* (maria.recalde@unimelb.edu.au) is an Assistant Professor in the Department of Economics at the University of Melbourne, Australia.

${ }^{*}$ Corresponding author

Notices

${ }^{1}$ IFPRI Discussion Papers contain preliminary material and research results and are circulated in order to stimulate discussion and critical comment. They have not been subject to a formal external review via IFPRI's Publications Review Committee. Any opinions stated herein are those of the author(s) and are not necessarily representative of or endorsed by IFPRI.

${ }^{2}$ The boundaries and names shown and the designations used on the map(s) herein do not imply official endorsement or acceptance by the International Food Policy Research Institute (IFPRI) or its partners and contributors.

${ }^{3}$ Copyright remains with the authors. The authors are free to proceed, without further IFPRI permission, to publish this paper, or any revised version of it, in outlets such as journals, books, and other publications. 


\begin{abstract}
We study the validity of experimental methods designed to measure preferences for intra-household resource control among spouses in Ghana and Uganda. We implement two incentivized tasks; (1) a game that measures willingness to pay to control resources, and (2) private and joint dictator games that measure preferences for resource allocation and the extent to which those preferences are reflected in joint decisions. Behavior in the two tasks is correlated, suggesting that they describe similar underlying latent variables. In Uganda the experimental measures are robustly correlated with a range of household survey measures of resource control and women's empowerment and suggest that simple private dictator games may be as informative as more sophisticated tasks. In Ghana, the experimental measures are not predictive of survey indicators, suggesting that context may be an important element of whether experimental measures are informative.
\end{abstract}

JEL codes: C9, D13, J12, J16

Keywords: intra-household resource control, women’s empowerment, lab-in-the-field experiment, bargaining power 


\section{ACKNOWLEDGEMENTS}

We thank Michael O’Sullivan, Markus Goldstein, and Tricia Koroknay-Palicz for their collaboration. We are grateful to Patrick Lubega, Anusuya Sivaram, Tigist Ketema, Ludovica Cherchi, Mashwal Ndego, Sadat Amandi, Francesca Viola, and Krutika Ravishankar for excellent research assistance and project management. We also thank all members of our data collection team at Economic Development Initiatives and Innovations for Poverty Action Ghana. Ethical approval to conduct this research was obtained from institutional review boards at IFPRI, the University of Ghana, the International Health Sciences University in Uganda, and from the Uganda National Council for Science and Technology. This work was funded by the World Bank, USAID, and Government of Ghana's Ghana Commercial Agriculture Project, the World Bank’s Umbrella Facility for Gender Equality, Africa Gender Innovation Lab, and a DECRG grant, as well as by the CGIAR Program on Policies, Institutions, and Markets, and IFPRI's Strategic Innovation Fund. Recalde also gratefully acknowledges financial support from the University of Melbourne and the Australian Research Council. Declarations of interest: None. 


\section{Introduction}

Measuring individual decision power within households is difficult. Economists typically use one of two approaches to study and empirically identify how much say someone has in the household. One approach consists of using rich consumption data sets, which also often contain information on labor supply, leisure, prices, and home production, to estimate household models of behavior (Chiappori and Mazzocco 2017). These models can identify the pareto weights associated with individual preferences in intra-household bargaining models, which have a natural interpretation as the relative say or decision power each person has in the household. Another empirical approach uses rich household survey data with modules designed to measure specific aspects of intra-household behavior such as individual agency, access to resources, decision-making power over expenditure categories, marital quality, and domestic violence. In this paper, we investigate a third approach, studying whether two simple, incentivized measures of resource control elicited from spouses in a lab-in-the-field experiment provide an alternative way to measure individual decision-making power within households.

Our lab-in-the-field experiment consists of two tasks. Task 1 measures willingness to pay for resource control in the household by having participants make two binary decisions. During the first decision participants choose which spouse should receive a sum of money. During the second decision, a tension between household income maximization and preferences for resource control is introduced: we ask participants whether paying 50 percent more money to the household, conditional on all resources being paid to the spouse not chosen in the first decision would change their decision. This simple two-step decision provides a coarse measure of willingness to pay for intra-household resource control. The second task asks participants to make two dictator game decisions in which they divide a sum of money between the couple. One decision is made in private and one jointly by spouses. Private dictator game decisions allow us to measure individual preferences for resource control and the degree of preference alignment between spouses. The private and joint decisions allow us to study how much influence each spouse has over the joint resource allocation decision made by the spouses.

Dictator games are appealing due to their simplicity. However, because there is no tension between household income maximization and resource control decisions, dictator game choices can be undone at home at no monetary cost to the household. To address this issue and make it incentive compatible for participants who desire more resource control to reveal their true preferences in the experiment, a lottery was conducted which could determine earnings for the couple. This lottery allowed participants to control the privacy of their decisions and hide income from each other outside of our study.

The experiment was conducted in two study sites located in Ghana and Uganda, with a total of 3,388 couples. Both study samples were chosen because they include participants from a population where there are important gender asymmetries within households. Additionally, understanding intra-household resource allocations is particularly important in the developing world, where household dynamics interact with social programs aimed at poverty alleviation and economic development. Furthermore, randomized controlled trials were scheduled to take place after our experiment at both study sites. These studies collected extensive baseline household survey data on intra-household decision making, which we use to study the validity of our incentivized measures of resource control as proxies for empowerment.

Results reveal robust gender differences in preferences for resource control within households. Across study sites, we find that women have a higher willingness to pay for resource control than men, and that they have lower influence over joint decisions in the dictator game. These results indicate that women have lower resource control in the household and have less influence over joint decisions in the experiment. 
Since dictator game choices can be undone at home at no cost to the household, and participants who do not hide income need not reveal their true preferences in the experiment, we study the correlation between dictator game choices and willingness to pay for resource control. This allows us to assess validity of dictator game choices as measures of resource control in the household. Results reveal a strong correlation between how much women choose to keep for themselves in the dictator game and their willingness to pay for resource control in both study sites. There is also a positive correlation between women's willingness to pay for resource control and lower influence over joint dictator game decisions in both countries. This exercise validates dictator game decisions as a measure of resource control in the household and tells us that both variables are picking up similar underlying latent variables.

To assess the validity of our experimental measures as proxies for empowerment, we also ask how predictive they are of household behavior outside of the experiment. Using household survey data, we construct indices of a broad range of variables representing different domains of women's empowerment and resource control, including preference alignment, domestic violence, decision making, access to resources, and marital quality. We then study how predictive our experimental measures are of these survey measures of empowerment.

Results reveal no systematic correlation between our experimental measures of resource control and the survey indices in Ghana. However, we find strong and systematic correlations between our incentivized measures of resource control and the survey measures in Uganda. Willingness to pay for control of resources is negatively associated with empowerment as measured by the survey measures. The strongest and most robust correlations show that women who keep more for themselves in the private dictator game are less empowered, suggesting that they intend to take advantage of the opportunity to hide income. Similar correlations are documented when considering the distance between private and joint dictator game decisions and the alignment of husband and wife preferences.

Our paper contributes to the literature along several dimensions. First, while previous studies have used lab-in-the-field experiments to elicit incentivized measures of intra-household resource control and bargaining power (e.g. Schaner 2017, Almas et al 2018; see section 2), most studies elicit only one measure, typically after an intervention has occurred, and sometimes from one spouse only. We collect two incentivized measures of resource control from both spouses before any intervention has occurred and conduct a systematic investigation of how well the measures perform against each other and relative to a set of rich household survey variables. This allows us to assess the validity of the incentivized measures of resource control we use. Several papers have conducted similar exercises to validate experimental and survey measures of preferences at the individual level (e.g. Dohmen et al 2011, Vieider et al 2015, and Falk et al 2016, Buser et al 2020). We bring this approach to the growing literature that makes use of intrahousehold experiments. ${ }^{1}$

Second, we conduct our experiment in two study sites, using a large sample of households located in two different countries, which provides some information about the generalizability of our findings. For example, the robust correlation between willingness to pay for resource control and dictator game decisions that we find in both countries gives credence to our validation of dictator games as a measure of resource control in the household. While previous work has used dictator games to study intra-household decisionmaking and to proxy intra-household bargaining power (e.g. Schaner 2017), they have not directly investigated what dictator games measure when played by spouses. The differences between the correlation of survey and experimental variables across study samples, is also informative for researchers seeking to

\footnotetext{
${ }^{1}$ Papers using a specific incentivized task to study aspects of intra-household behavior and resource control have reported correlations between the survey measures and the experimental measures they collect. However, there is typically not a systematic reporting of correlations between variables. In section 2 we provide a review of the literature that also describes the correlations documented by past studies.
} 
understand when incentivized measures of resource control may be able to capture behavior of interest outside of the experiment. The Ugandan sample, in which we document strong correlations between the experimental measures and survey indicators, is one where households are involved in commercial farming and accustomed to monetary transactions. Conversely, the Ghanaian sample is heavily reliant on subsistence farming and has a relatively non-monetized economy, suggesting that such experimental measures may be less useful in situations where financial literacy is low.

The paper proceeds as follows. Section 2 reviews the literature using lab-in-the-field experiments to measure aspects of resource control in the household. Section 3 describes the experimental design. Section 4 describes the study samples and implementation procedures. Sections 5-7 present our results, while section 8 concludes.

\section{Background on experimental measures of intra-household resource control}

The use of lab experiments to study various aspects of intra-household decision making is a growing area of research. ${ }^{2}$ In this section we discuss the development of experimental tasks that address the question of preferences for resource control in the household, specifically among married couples. ${ }^{3}$

A primary class of tasks used by researchers to directly measure resource control in the household are dictator games. In a standard dictator game, the decisionmaker divides an endowment between themselves and another person. When the game is played with strangers, it measures altruism. However, when played among spouses the game speaks to the dictator's willingness to share resources with their spouse and thus his or her preference for resource control in the household. A joint decision on allocation of the endowment following private decisions made by each spouse can also be used to measure resource control by quantifying how close the joint allocations are to the private preferences of each spouse.

It is true that in a household where either the preferences of spouses are perfectly aligned, spouses pool income, or spouses perfectly communicate with each other, it does not matter who controls income. In such cases, the standard dictator game need not measure resource control. However, in a household where there is not perfect preference alignment and spouses may hide income from each other, dictator game choices can reveal information about intra-household dynamics. In one example in a study in Kenya, Schaner (2017) uses the standard dictator game to elicit private and joint decisions from spouses and construct an experimental estimate of the bargaining power of each spouse. She finds that this measure is positively correlated with a demographic proxy of bargaining power, but uncorrelated or negatively correlated with survey measures related to decision-making power in spending and saving decisions. ${ }^{4}$

The dictator game is useful in its simplicity but suffers from the drawback that, in some households, decisions can be reversed outside of the game at no cost. As such, another stream of experimental measures introduces a trade-off between maximizing household resources and controlling income. One such game is the modified dictator game, in which the amount transferred by the decisionmaker is multiplied by an

\footnotetext{
${ }^{2}$ Some examples include studies that test properties of household models (Peters et al. 2004, Bateman and Munro 2005, Iversen et al. 2011), study the role of informational asymmetries within households (e.g., Ashraf 2009, Castilla and Walker 2013, Ambler 2015, Hoel 2015, and Castilla 2019), or examine preference heterogeneity and joint decisions in the domains of risk and time (e.g., Carlsson et al 2012, 2013).

${ }^{3}$ This review is not exhaustive. We restrict attention to experiments conducted with couples, that elicit decisions over money rather than real effort or consumption, and that study resource control separately from risk or time preferences. For a more comprehensive review of the literature using intra-household experiments see Munro (2018).

${ }^{4}$ Another study that uses the standard dictator game to study intra-household decision-making but only elicits private decisions from spouses is Holden and Bezu (2013), who document a positive relationship between the amount spouses allocate to the wife in the dictator game and attitudes about women's land rights in Ethiopia.
} 
amount greater than one, such that total household resources are maximized by transferring income to your partner. The game thus measures willingness to sacrifice household resources to control income. The main drawback of this approach is that it cannot distinguish whether higher transfers result from a lower desire for resource control, altruism, or efficiency concerns.

Modified dictator games have been used to study whether households maximize joint income (Iversen et al 2011, Kebede et al 2014, Cochard et al 2016, Mani 2020) and the resource allocation decisions made by spouses. Hoel (2015) elicits choices in modified dictator games under public and private information conditions and shows that more knowledge about resources at home is associated with higher levels of opportunism in the lab in this subset of households. Jack et al. (2018), on the other hand, find that households that make higher transfers and thus behave more efficiently in a private modified dictator game are more sensitive to water prices in a field experiment that provides financial incentives for households to consume less water. Additionally, the intra-household efficiency measure is positively correlated with survey measures of joint decision making.

A related task, which is perhaps the most commonly used in the literature to indirectly measure resource control in the household is the linear public goods game. In this game, each partner receives an endowment and must decide how to allocate it between a private and a joint account. All contributions made to the joint account are multiplied (for example by 1.5) and are split equally between partners, while money placed in the private account is kept by the decision maker, introducing a tension between household income maximization and retaining control over resources. A spouse who wishes to maximize household resources should contribute everything to the joint account, while a spouse who wishes to retain control over resources may instead choose to sacrifice some household income by keeping part or all of the endowment. ${ }^{5}$

Analysis of correlations between behavior in public goods games and field behavior has shown mixed findings. For example, Castilla (2019) conducts an experiment that combines a linear public good game with an ultimatum game and documents some positive correlations between women's cooperation in the lab and survey measures of decision-making power at home. However, Lowes (2018) finds the opposite result. Lowes (2018) shows that in matrilineal households, where women have higher outside options and thus higher bargaining power relative to patrilineal households, the cooperation rates of husbands and wives are lower, yet the well-being of matrilineal women is higher.

Recent studies have employed a new approach comprised of binary decisions to directly measure willingness to sacrifice household resources to control income. ${ }^{6}$ For example, Fiala and $\mathrm{He}(2017)$ and Fiala (2018), ask participants to choose between $X$ paid to them or $M X$ paid to their spouse. As in linear public good games and modified dictator games, parameter $M=1.5$ introduces a tension between resource control and household income maximization. Almas et al (2018) instead have participants make similar decisions but in a series of binary choices designed to more precisely elicit willingness to sacrifice household resources to control income. The first decision asks participants to choose between $\left(1 / M_{1}\right) X$ paid to them

\footnotetext{
${ }^{5}$ The linear public goods game has been used by researchers to study whether spouses maximize joint income (Iversen et al 2011, Kebede et al 2014, Munro et al 2014, Lopez et al 2015), income concealing in the household (Castilla 2019), and the role of social norms and spite in intra-household resource control decisions (Mani 2020). It has also been used to compare spousal cooperation rates across different types of households (e.g. Barr et al 2019, Munro et al 2019, Lowes 2018, Hoel et al 2019, and Lecoutere and Jassogne 2019). Barr et al (2019) and Munro et al (2019) compare monogamous and polygamous households, Lowes (2018) compares households with different kinship systems, while Hoel et al (2019) and Lecoutere and Jassogne (2019) classify households into types based on their lab behavior and study the correlation between these types and smallholder agricultural practices in the field. Another study that examines the correlation between lab measures of intra-household resource control and agricultural practices is Lenjiso et al (2016), but they use a coordination game instead of a public goods game.

${ }^{6}$ Binary decisions have also been used to study the trade-off between equality and efficiency in intra-household resource allocation. See, for example, Beblo et al (2015) and Cochard et al (2016).
} 
or $X$ paid to their spouse. As in other studies, $M_{1}>1$ to ensure that there is a trade-off between retaining resource control and maximizing household resources. Depending on the choice made by the decision maker, the next choice changes $M_{k+1}$ up or down. The experiment ends when the participant starts to switch between choices, and thus signals that they have reached a range of indifference between options.

While Fiala and He (2017) use their lab experiment to test the unitary model of the household, Fiala (2018) uses it to identify income hiding in the household and examine heterogeneous treatment effects of an RCT conducted with microenterprise owners in Uganda. ${ }^{7}$ Almas et al (2018) instead use their lab experiment to measure the impact of a cash transfer program in Macedonia. Results show that wives who received the cash transfer were willing to forego less to control income than women who did not receive the transfer. However, this measure is not robustly correlated with survey measures of resource control.

Almas et al (2018) make an important methodological contribution, but similar to other tasks, the method is not capable of perfectly measuring intra-household resource control. This is because a zero willingness to sacrifice household resources to control income may mean several things. It may be an indicator of preference alignment in the household, of full resource control by wives, or wives having such low bargaining power that the incentives used in the game are not enough to make it worthwhile for women to forego household resources to change the bargaining weights of household members. The Almas et al (2018) design is also not easy to implement in samples where literacy levels are low.

The existing literature has described useful experimental measures of intra-household resource control and provided some mixed evidence on their correlation with survey-based measures. The experiment we conduct builds upon these studies by conducting a within-subject experiment that elicits multiple measures of preferences for resource control from the same couples, allowing us to investigate how the different experimental measures correlate with each other and with household behavior outside of the experiment. The first task incorporates a tradeoff between household income and resource control, and is based on Almas et al (2018). However, we make some modifications to simplify the task and adapt it to a population with lower literacy levels. These modifications were necessary with our study samples, and make the experimental measure easier to elicit in developing country settings, but do make our measure a much coarser proxy of willingness to pay for resource control. The second task measures preferences for resource control using the standard dictator game, incorporating private decisions followed by a joint decision. ${ }^{8}$ The next section describes our experimental design in detail.

\section{Experimental design}

We designed a lab-in-the-field experiment to elicit two incentivized measures of preferences for resource control from spouses. Each measure was collected using a separate experimental task, which consists of one or more decisions that could determine earnings for both spouses. Participants knew at the beginning of the experiment that they would be making several decisions and that only one decision made by the couple would be randomly selected to be paid. They were also informed that a separate lottery could determine the earnings of both spouses, and that neither they nor their spouse would find out whether a lottery or a decision determined earnings and whose decision was chosen to be paid. Below we describe the tasks and what they are designed to measure. The goal of the paper will be to characterize the validity of

\footnotetext{
${ }^{7}$ This RCT provided loans, grants, and training to participants and showed no impact of any capital treatment on the average enterprise owner. Analysis of heterogeneous treatment effects, however, revealed positive impacts for men who are not willing to sacrifice household resources to control income, and negative impacts for men who do. The opposite is true for women; those who maximize household resources in the lab experiment show negative impacts of the capital treatments, while those who do not show positive impacts.

${ }^{8}$ Like Schaner (2017), we elicit private and joint decisions from spouses. However, our choice set is different because we prevent the equal split from being a choice option.
} 
these measures by assessing how they correlate with each other and how they map onto household behavior outside of the experiment.

\subsection{Task 1: Willingness to pay to control resources}

Task 1 measures individual willingness to sacrifice household resources to control income using a two-step procedure. The first decision asks individuals to choose who in the household should receive a sum $X$ of money, themselves or their spouse. The second decision asks participants if $1.5 X$ paid to the spouse not chosen in stage 1 would change their decision. Specifically, if the decision maker chooses to be the recipient in stage 1 , we ask the decision maker in stage 2 to choose between $X$ paid to them or $1.5 X$ paid to their spouse. If instead the decision maker chooses not to be the recipient in stage 1 , then we ask the decision maker in stage 2 to choose between $1.5 X$ paid to them versus $X$ paid to their spouse. Participants knew at the beginning of the task that they would be making two decisions but not what each decision entailed.

Payoffs in the experiment were chosen in such a way that the average amount of resources earned by the household was roughly equivalent to twice the daily wage that participants could have earned in the study area. This made the decision meaningful and ensured that the two decisions elicited from spouses introduced an important tradeoff between household income maximization and the preference over who in the household should control income. If the decision-maker chooses to give up $0.5 \mathrm{X}$ to receive income, then the participant is willing to sacrifice at least $50 \%$ of the endowment to control income. If the decision maker chooses to give up $0.5 X$ to let their spouse receive the income, then the participant is willing to pay $-0.5 X$ to control resources (or to give up at least $50 \%$ of the endowment to have their spouse control resources).

This task was designed to identify households where the desire to control resources may lead to households failing to maximize household income. Either spouse is likely to give up resources to maintain control if they do not believe that the money will be spent in accordance to their preferences if given to their spouse. Cases where the respondent does not choose to give up income are indicative of a household where the benefit of maintaining control is not greater than the resources that would be lost, and suggestive of a more cooperative relationship. Finally, the choice to give up income in order for their spouse to maintain control could be suggestive of self-control issues on the part of the respondent or extreme norms or preferences related to who should receive the money.

\subsection{Task 2: Dictator game}

Task 2 asks participants to make two decisions. In each decision participants must divide a sum $Y$ of money between themselves and their spouse. The choice set available to participants does not change across the decisions; it is discrete, contains 8 choices, and by design excludes an even split between spouses as a choice option. This design choice forces participants to choose an unequal resource division and was done to reduce any experimenter demand effect that may arise from participants' potential perception that an equal split of resources is preferred by the experimenter.

Choices were first made individually by each spouse in private, and then jointly by spouses after they were given the opportunity to deliberate face to face away from others. Participants did not know when making their private decision that they would be repeating the same decision together with their spouse. Stakes were similar to Task 1 . However, the stakes in Task 1 and Task 2 were not identical, in order to frame decisions in the two tasks differently and to accommodate the desired design features.

Private dictator game decisions reveal individual preferences for resource allocation between spouses in the game. The difference between private and joint decisions allows us to study how private and joint 
decisions differ and thus how much influence each spouse has over joint dictator game decisions in the experiment. As highlighted in the previous section, one drawback to this task is that because there is no tension between household income maximization and resource control in the dictator game, choices can be undone at home by spouses at no monetary cost to the household. ${ }^{9}$ However, in households where there is competition over resource control and at least one spouse hides income, it is incentive compatible for participants to reveal their true preferences in the private dictator game.

\subsection{Lottery}

Before spouses made the incentivized choices in each of the tasks discussed above, we conducted a lottery that pays $\left(z_{A}, z_{B}\right)$ to spouses. Variable $z_{i}$ is independently and uniformly distributed over $[0, \bar{Z}]$ where $i=$ $A, B$ denotes the two spouses and $\bar{Z}$ represents the maximum earnings that can result from a decision made by a spouse in the experiment. This lottery was implemented by having each spouse draw a lettered card from a deck, where each letter had a unique value associated with it. Participants did not learn the outcome of the lottery, only that all possible payment outcomes in the experiment could result either from decisions made by either spouse or from random chance. This lottery is a crucial design feature because it allows participants to control the privacy and confidentiality of their decisions outside of the experiment. ${ }^{10}$

\subsection{Other experimental design features}

The lottery was implemented first, to explain to participants in subsequent tasks that their private decisions could not be revealed directly or indirectly to their spouse during or after the experiment. After the lottery was conducted, Tasks 1 and 2 were conducted in fixed order. At the end of the experiment either the lottery, or one of the decisions made by spouse A or B in Task 1 or 2 was randomly selected to be paid. ${ }^{11}$

No feedback about earnings or the decisions was provided to participants throughout the experiment. Payment was done in private at the end of the study, using procedures that guaranteed the privacy and confidentiality of decisions. For example, spouses never learned which task or decision was randomly selected to count for payment, or what private decisions their spouse made in the study. They were also not provided copies of receipts to avoid any risk with others seeing their earnings.

\section{Study samples}

We conducted the lab-in-the-field experiment described above using two study samples. One sample includes 1,025 couples who had expressed interest in participating in a randomized controlled trial conducted by an agribusiness in the Upper East Region of Ghana. When households expressed interest in participating in the RCT, they were asked to sign up as a couple. Interest in the trial was based on the couple's desire to rent irrigated land and their willingness to have a potential rental contract randomly assigned to either the husband or wife. In polygamous households, the household could choose which wife would be enrolled. Households surveys regarding decision-making and preference alignment were conducted during in-home visits between March and September, 2016. Once households in a village had

\footnotetext{
${ }^{9}$ This is problematic for joint decisions in all types of households, and for private decisions in households where spouses pool income, have perfectly aligned preferences, or communicate perfectly with each other, because all choices in the game are theoretically equivalent in these scenarios.

${ }^{10} \mathrm{We}$ chose to implement the lottery using a deck of cards to make it salient to participants that a lottery was conducted and that they could hide income from their spouses outside of the experiment if they wished to so. Each card in the lottery had a code associated with it. This code was entered by enumerators in the tablet used to record decisions. Neither the participant nor the enumerator knew what value was associated with each card and code during the study.

${ }^{11}$ In one of our study sites, Ghana, Task 2 also elicited investment decisions from spouses. These decisions measure risk preferences and are included in the script included in Appendix A.
} 
been interviewed, the lab-in-the-field experiment invited couples to a "meeting." This meeting took place in a central location in the village and simultaneously elicited incentivized decisions from spouses. Private interviews were conducted first, by two enumerators who privately interviewed each spouse in a separate interview booth. Joint decisions were elicited afterwards, by one enumerator after spouses were brought together. Thereafter, participants were paid. An interview with each couple took approximately 30 minutes to complete in Ghana. A detailed description of the experimental procedures used in this study site is provided in Appendix A.

Our second study sample includes 2,363 couples who were part of randomized controlled trial conducted near Jinja, Uganda (Ambler, Jones, and O'Sullivan 2019). ${ }^{12}$ The trial sample included small-scale sugarcane contract farmers who held contracts with a specific, large sugarcane buyer. If located, each contract farmer registered with this buyer was enrolled in the study, conditional on being married. One husband and one wife were enrolled per study household. In polygamous households, the wife most involved in sugar production participated. The lab-in-the-field experiment was implemented together with the baseline survey of the RCT, between July and September, 2016. Households were interviewed at their homes, by one enumerator. Incentivized decisions were elicited first, followed by the household survey. The spouse readily available, who the couple agreed should be interviewed first, made private decisions first. Afterwards, the second spouse was interviewed privately. After both spouses made their private decisions, the couple was brought together to make the joint decision. Afterwards, the enumerator proceeded with the household survey. It took approximately 30 minutes for the enumerator to elicit incentivized decisions from both spouses, and approximately 2.5 hours for the household survey to be administered. Participants were paid at the end of the household survey; however, payment was not contingent upon participation in the household survey. A detailed description of the experimental procedures used in Uganda is provided in Appendix B.

Table 1 summarizes some basic characteristics of the participating households. These demographic characteristics show some similarities between the households in the two countries. Households are only slightly larger in Ghana (9.12 members compared to 8.7 members), and approximately one third of households are polygamous in both samples. Couples have been married approximately two years longer in Ghana. The Ghana sample is slightly older for both wives (39 versus 38.3 ) and husbands (48.6 versus 46.6). Despite these similarities, education levels are very different. In Ghana, education is extremely low; $78 \%$ of wives and $59 \%$ of husbands have no formal education. In Uganda, however, those numbers are only $18 \%$ and $6 \%$ respectively. $44 \%$ of wives and $60 \%$ of husbands in Uganda have completed primary or higher. This education statistics are indicative of a major difference between the two samples. The Ghanaian sample is composed primarily of households engaged in subsistence agriculture who reside in a remote area, while the Ugandan sample is defined by its engagement in commercial agriculture. ${ }^{13}$

There are a few experimental design differences between study sites that are worth highlighting. First, the Ghana experiment was designed and piloted first and in addition to collecting incentivized measures of resource control, it also elicited private and joint investment decisions from spouses. These investment decisions measure risk preferences and were conducted in conjunction with the dictator game decisions. Participants made their private dictator game decision first, followed by two private investment decisions. Thereafter participants were brought together to make the joint dictator game decision and investment decision sequentially. ${ }^{14}$ Participants learned at the beginning of the task how many decisions they would

\footnotetext{
${ }^{12}$ The trial examines the impact of a pair of interventions designed to increase women's empowerment.

${ }^{13}$ All households in the Uganda sample have a relationship with a large sugar company that is based outside Jinja, a small to medium sized city with an active economy.

${ }^{14}$ Investment decisions were elicited using similar procedures to Ambler, Godlonton, Recalde (2020). Participants chose how much of an endowment $W$ to invest in an account that pays three times the amount invested with 50\% probability and 0 otherwise. $W$ represents approximately the daily wage in the study area. Only the order of private
} 
make but not what each decision entailed. Decisions were described in detail only when participants were presented with a decision.

Second, implementation procedures were different in our Ghana and Uganda study sites. In Ghana the baseline survey was conducted in two parts, the first approximately one to three months prior to the collection of the experimental measures and the second two to three months after. We use survey data from the first visit to construct the survey measures of empowerment. ${ }^{15}$ The Ghana experiment was conducted in central locations with several couples participating at the same time. Multiple enumerators were at each session and thus spouses were interviewed simultaneously. This setup provided a high degree of control over experimental procedures and allowed us to collect data from all households residing in the same geographical area in a short time. The Uganda experiment was conducted by one enumerator per couple at each couple's home during the same visit as the baseline survey. As such the investment decisions were not included to reduce the time spent, and implementation procedures were modified as needed. However, the way in which incentivized decisions were elicited was not changed across study sites.

A third difference between study sites are the payoffs used to elicit decisions. In Ghana, the stakes at play in Tasks 1 and 2 were $X=10 G H C$ and $Y=14 G H C$ respectively. These values do not change across households in Ghana, but they do in Uganda where $X=10,000$ UGX in all households, while Y could be either $14,000 U G X$ or 28,000 UGX. One fourth of the sample in Uganda was randomized into the high stakes environment. The stakes were designed to be roughly comparable across sites with $Y$ in Ghana equal to approximately $\$ 3.66 \mathrm{USD}$ and the low-stakes $Y$ in Uganda equal to approximately $\$ 4.14 \mathrm{USD}$. This translates to similar expected earnings across all households at each study site, which is approximately twice the daily wage a participant could have earned in the study area.

\section{Experimental data}

In this section we describe the experimental data in both countries. Doing so allows us to characterize behavior in the experiment before assessing how well the experimental measures perform relative to each other and how predictive they are of self-reported household survey outcomes.

Figure 1 shows the distribution of individual willingness to pay to control resources (Task 1) for Ghana in Panel A and Uganda in Panel B. The variable can acquire three values: 0.5 indicates that the participant is willing to sacrifice $50 \%$ of the endowment to control resources, 0 indicates that the participant is not willing to give up resources to assign control to either themselves or their spouse, and -0.5 indicates that the participant is willing to pay to give resource control to their spouse. Panel A reveals that in Ghana, the majority of both husbands and wives do not sacrifice resources to determine who in the household should control income. Around $30 \%$ of husbands have a negative willingness to pay for resource control, i.e. they pay for their wife to control resources, while $15 \%$ pay to maintain resource control themselves. The wives' responses show that $20 \%$ pay for their husband to control resources while $20 \%$ pay to maintain control themselves. Thus, the overall distribution of choices shows that women have a higher willingness to pay for resource control than men.

In Uganda, the distributions of responses look different, but tell a similar story: women have a higher willingness to pay for resource control than men. About $40 \%$ of both husbands and wives are not willing to pay to shift control of resources. $40 \%$ of husbands and approximately $35 \%$ of wives are willing to pay to

\footnotetext{
investment decisions was randomized across couples; the order of all other decisions and tasks was fixed. See Appendix A for a script and experimental procedures used to elicit all decisions in Ghana.

${ }^{15}$ In the event that a registered household had not received the first survey visit prior to the lab-in-the-field experiment, we conducted the corresponding household survey immediately after the couple participated in the experiment.
} 
have their spouse control resources, and around $20 \%$ of husbands and $24 \%$ of wives are willing to pay to maintain resource control.

The distribution of choices by gender tells us that women are generally more willing to pay for resource control than men in our data. Comparing behavior within households allows us to classify households into types. For example, those that behave efficiently and maximize household income in the experiment represent $35 \%$ of households in Ghana and 22\% of households in Uganda. Households where women are more willing to pay for resource control than their husbands represented $35 \%$ of households in Ghana and $29 \%$ of households in Uganda, while households where men are more willing to pay than wives represent $21 \%$ and $24 \%$ of households in the Ghana and Uganda samples, respectively.

Next, we examine choices in the dictator game. We use the share of the endowment assigned to the wife as our main variable to make the analysis comparable across countries and to normalize the difference in stakes in the Uganda sample. Figure 2 shows the CDFs for the amounts assigned to the wife by the wife, by the husband, and in the joint decision separately. In Ghana, the three distributions are fairly similar, but suggest that women assign themselves slightly less than men assign them while joint decisions are more common near the center of the choice set. In Uganda, the differences between men's and women's allocation are larger and show that the women assign themselves more money than men assign them. Joint decisions in Uganda are also more common towards the middle of the choice set.

The within-household differences in the allocation decisions are examined in Figure 3. In Ghana, we document that the Joint-minus-Husband difference $(\mathrm{J}-\mathrm{H})$ is most likely to be zero, indicating that the husband's preferences are most likely to be reflected in the joint decision. The Joint-minus-Wife (J-W) difference also has a higher mass at zero than the difference between private decisions (Husband-minusWife, H-W), though by a much smaller amount than the J-H curve. This is indicative of a pattern in which the joint allocation most similarly reflects the husband's preferences, but in which the wife's preferences do have some influence. The J-H and J-W curves suggest that $60 \%$ of husbands and $40 \%$ of wives have full say over the joint decision. However, part of this is driven by households with perfectly aligned preferences as the $\mathrm{H}$-W curve reveals that $25 \%$ of spouses make the same private allocation decisions. There is a similar pattern in the Uganda data, though differences between the curves at the negative values are larger, indicating a greater propensity for the amount assigned to a wife to be larger when assigned by the wives than by the husband or jointly. The mass at zero for all curves is also lower, although the comparison between curves is similar. ${ }^{16}$

To better understand the difference between wife and husband responses within households we conduct a series of regressions to estimate the average gender difference in responses using household fixed effects. We examine two indicators from each task: a binary variable taking the value of one if the respondent indicated a positive willingness to pay to control resources (WTP $=0.5$ in Figure 1), a binary variable equal to one if the respondent indicated a negative willingness to pay to control resources (WTP $=-0.5$ in Figure 1), the percent of the endowment allocated to the wife in the private dictator game decision, and the absolute value of the distance between the private allocation to the wife and the joint allocation to the wife. We estimate the following equation:

$$
y_{i h}=\beta w i f e_{i j}+\gamma_{i h}+\delta_{h}+\varepsilon
$$

Where $y_{i h}$ is one of the described outcome variables for individual $i$ in household $h$. wife $_{i j}$ is an indicator for whether the respondent is the wife or husband, $\gamma_{i h}$ is a vector of individual-level control variables that includes age, years of schooling, income, and savings, and $\delta_{h}$ is the household fixed effect. $\beta$ is an estimate

${ }^{16}$ The private decisions made by both spouses coincide with the joint decision made by the couple in $18 \%$ of the households in Ghana and 14\% of the households in Uganda. 
of the within-household difference between wife and husband responses. Standard errors are clustered at the household level. The results are reported in Table 2 with Ghana in Panel A and Uganda in Panel B.

The results related to willingness to pay to control resources are reported in columns 1 through 4 . Columns 1 and 2 show regressions estimating the difference between wives and husbands being willing to pay to control resources, without and with control variables, respectively. Columns 3 and 4 show the same for being willing to pay for the spouse to control resources. The estimates show that in Ghana a woman is five percentage points more likely to be willing to pay to control resources than her husband, and approximately nine to 11 percentage points less likely than he is to pay for her spouse to control resources. We document the same pattern in Uganda, though the magnitudes of the coefficients are smaller; a woman is approximately three percentage points more likely to pay to control resources, and 5.5 to 8.5 percentage points less likely to pay for her spouse to control resources.

In columns 5 through 8 , we examine the responses in the dictator game, reporting the percentage assigned to the wife in columns 5 and 6 , and the absolute distance between the private allocation to wife and the joint allocation to wife in columns 7 and 8 . In Ghana, a woman assigns slightly less to herself than her husband assigns to her, on the order of two percentage points. However, the distance from the wife allocation to the joint allocation is also larger for a woman, around 8 percentage points. This is a substantial difference, particularly when compared to the average among husbands of 9 percentage points. In Uganda, a women does allocate more to herself than her husband assigns to her ( 7 to 8 percentage points) and experiences a larger gap between private and joint allocation of 6 to 7.5 percentage points, roughly 50 percent of husbands' average.

The results presented here show that women are more willing to pay to control resources than their husbands and less willing to pay for their spouse to control resources, which indicates that they have lower control over household income outside of the experiment. At the same time, women experience larger differences between their private allocation and the joint allocation in the dictator game, which is indicative of lower influence over decisions regarding household resources. The analysis to follow in this paper will explore the extent to which dictator game decisions capture preferences for resource control in the household, and whether the incentivized measures we elicit capture household behavior outside of the experiment that is often associated with higher levels of women's empowerment.

\section{Correlation between experimental measures}

By design, Task 1 measures willingness to pay for resource control in the household. However, as indicated in Section 3, dictator game choices need not identify preferences for resource control in households where spouses do not hide income because choices can be undone at home by participants at no cost to the household. In this section, we study the extent to which behavior in the willingness to pay task is correlated with behavior in the dictator game. Studying this correlation allows us to assess the extent to which dictator game choices reflect preferences for resource control in the household, and to study the extent to which these measures are picking up similar or different aspects of household behavior.

To investigate the correlation between measures, we estimate an OLS regression model with a willingness to pay measure as the dependent variable and an indicator from the dictator game as an independent variable. We also include individual and household level control variables. The individual controls (as in the previous regressions) include age, years of schooling, income, and savings. The household controls are measures of food security, wealth, household income, and household savings. The models are run separately for wives' responses and husbands' responses. The results for wives are shown in Table 3, with Ghana in 
Panel A and Uganda in Panel B. The corresponding models using husband responses are in Appendix Table $1 .{ }^{17}$

Columns 1 through 4 of Table 3 show correlations with the indicator for being willing to pay to control resources and columns 5 through 8 with the indicator for being willing to pay for the spouse to control resources. The first two columns of each set examine the correlation with the percentage assigned to the wife by the wife in the private dictator game decision, both without and with the addition of the percentage assigned to the wife by the husband and the percentage assigned to the wife in the joint decision. The next two columns examine the absolute distance between the wife's allocation to herself and the joint allocation to the wife and the absolute distance between the wife's and husband's private allocations to the wife. In both cases, we include an indicator to control for the sign of the difference, though excluding it does not substantially change the results.

In Ghana we document strong correlations between the experimental measures. The percent of the endowment assigned by wives to themselves is strongly positively correlated with women's willingness to pay to control resources. Interestingly, the addition of the husband's allocation to the wife and the joint allocation to the wife to the model do not change this relationship. We also document a positive correlation between the absolute distance between the wife's private allocation and the joint allocation, as well as between the wife's allocation and the husband's allocation. In Uganda a similar pattern is documented between the wife's allocation to herself and her willingness to pay to control resources and between the distance measures and willingness to pay though the magnitude of the coefficients is smaller. The results in columns 5-8 regarding paying for spousal control of resources show generally opposite patterns, as expected, though the results are less robust. Overall, this analysis indicates that dictator game choices and willingness to pay for resource control measures are capturing some of the same underlying latent variation.

The corresponding analysis of husbands' responses is in Appendix Table 1. Men whose wives allocate more of the endowment to themselves are less likely to give up resources to maintain control in both countries. The joint allocation to the wife is also negatively correlated with the husband's willingness to pay to control resources, as is the husband's allocation to the wife in Uganda only. In Uganda we also document that larger differences between the joint allocation to the wife or the wife's allocation to the wife and the husband's allocation to the wife are negatively correlated with willingness to pay for resource control. In Ghana these coefficients are positive, but statistically significant only for the latter. We also note correlations in the opposite direction for willingness to pay for wife to control resources. In general, the male responses indicate that resources are allocated to women in households where men have less interest in controlling resources.

\section{Correlation with survey measures}

The study of women's roles in households and their empowerment more generally has driven the development of a large number of survey-based methods that seek to develop measures of various components of these concepts. In the final piece of our analysis, we study the correlation of our experimental measures with a range of survey indicators of women's bargaining power and their general level of empowerment in the household. To do this, we take advantage of the rich baseline data collected in both countries and create standardized indices for five categories of outcomes in each country following the method described in Kling, Liebman, and Katz (2007). In Ghana these are: intra-household preference alignment, psychological violence, physical violence, wife's access to resources, and wife's participation in decision making. The categories in Uganda are similar, but there is no module on psychological violence, and we also include questions related to marital quality. Because the surveys were not the same in each

\footnotetext{
${ }^{17}$ We present the results for wives as our leading models because some of the survey measures used in section 7 are elicited from wives only. It is also not uncommon in the literature to elicit measures from wives only.
} 
country, the variables that comprise each index vary somewhat. A full list of the variables in each index and their means are reported in Appendix Tables 2 and 3. ${ }^{18}$ For variables with categorical outcomes, we create a question-level outcome index that preserves the full variation in each variable, without treating them as continuous, following a method developed in Heath, Hidrobo, and Roy (2020) and Roy et al. (2019). A detailed description of the construction of the indices is in Appendix C.

The selected outcomes represent categories of survey questions commonly used to capture aspects of intrahousehold structure, bargaining power, and women's empowerment. Access to resources is one of the three domains of empowerment as defined by Kabeer (1999). A second domain, agency, is represented in our outcome measures by the index of participation in decision making. The third domain, achievement, is represented in our outcomes by absence of physical and psychological violence, as well as the marital quality index employed in Uganda. While intra-household preference alignment does not directly measure empowerment, more closely matched preferences may be a sign of a more cooperative household. Further, this measure also provides a comparison for preference alignment as measured by the dictator game.

The empirical strategy is the same as in the previous section, but the outcome variables are the survey measure indices, and the independent variables of interest are each of the experimental variables in turn. As before, we focus on wife's responses. The results for Ghana are in Table 4 and for Uganda in Table 5. The corresponding results for husband's responses are in Appendix Tables 4 and 5. ${ }^{19,20}$ Model 1 examines the relationship between the willingness to pay variables and the survey outcomes. The indicators for both positive and negative willingness to pay are included, with willingness to pay equal to zero as the omitted category. Model 2 examines the percent allocated to the wife in the dictator game by the wife, husband, and in the joint decision. Models 3 and 4 examine the absolute difference between the wife's allocation to herself and the joint allocation or the husband's allocation respectively. Models 3 and 4 also include a control for the direction of that distance.

In Ghana we find very little evidence of any robust correlation between the experimental measures and the survey measures (Table 4). The same is also generally true of the husband's responses (Appendix Table 4). However, in Uganda (Table 5) there are strong patterns of correlation. Wives' willingness to pay to control resources is negatively correlated with marital quality and wife's access to resources, and is positively correlated with women's decision-making power. Conversely, willingness to pay for spousal control of resources is positively correlated with preference agreement, access to resources, and decision making, while negatively correlated with domestic violence incidence. These results suggest that higher willingness to pay for resource control is an indication of lower female empowerment, though the correlation with decision making is anomalous. The results for the indicator of willingness to pay for spouse to control resources also reveal that it is not disempowered women who pay for their spouse to receive the money, but rather more empowered women who have less interest in controlling resources.

Examining the indicators from the dictator game (Model 2), we find that the percentage assigned to the wife by the wife is negatively correlated with preference alignment, marital quality, access to resources,

\footnotetext{
${ }^{18}$ The intra-household preference alignment variables vary the most by country. In Ghana, wives and husbands were asked separately the extent to which they agreed in a variety of categories. Therefore, we can construct a preference alignment measure based on wife responses and one based on husband responses. In Uganda, we instead ask respondents directly about their spending preferences and construct one measure indicating how much they align.

${ }^{19}$ Some of the outcomes are collected for both husbands and wives, in which case we use the husband response in the husband regression and the wife response in the wife regression. In Ghana these variables are preference alignment and decision making. In Uganda they are marital quality and decision making.

${ }^{20}$ In models B and D, the independent and dependent variables are the same in the husband and wife models, except for the cases noted where we use husband's reports for the outcome variable. The estimates differ slightly from the wife regressions because the individual-level controls are different. However, the results are essentially the same and included in the husband response tables only for completeness.
} 
and decision making, and positively related to domestic violence incidence. This indicates that women with low levels of empowerment assign higher amounts to themselves in the private dictator game. There is no strong pattern for the husband or joint allocations, suggesting that the women's allocation to herself alone is a more reliable indicator of low empowerment. This may be because joint decisions can be easily undone outside of the experiment and do not allow for income hiding. The fact that women who allocate larger amounts to themselves privately have higher willingness to pay for resource control and appear to be less empowered using household survey variables suggests that income hiding may be a key feature of their private dictator game decision.

We note these same significant correlations for distance from joint decision in Model 3 (marital quality, domestic violence, access to resources, and decision making) and distance from husband's decision in Model 4 (domestic violence, access to resources, and decision making) ${ }^{21}$ The husband responses (Appendix Table 5) tell a less robust story. These results suggest that in Uganda, the experimental measures are good proxies of a broad range of intra-household bargaining power and empowerment indicators, but do not necessarily pick up specific elements of household behavior. Women's responses are more predictive than men's, and in fact, if men are not available for interview, women's allocations to themselves perform similarly to the measures that include husbands' involvement.

\section{Discussion}

These results suggest that experimental measures show promise as simple proxies of women's resource control in the household, in Uganda in particular, where the experimental measures are highly correlated with survey measures of empowerment. In both countries, the consistency across measures suggests that they are measuring similar or correlated phenomenon and not necessarily different aspects of intrahousehold bargaining power. Dictator games in which women make allocations to themselves privately appear to be good proxies for resource control as they are correlated with other experimental measures and a range of survey measures. This occurs even though, theoretically, dictator game choices may not be the best measures of intra-household resource control as choices can be undone at home at no monetary cost to the household.

One of the interesting components of these results is the difference that we observe between countries. Though correlations between the experimental measures are documented in both countries, they are larger in magnitude in Ghana. In Uganda we observe much stronger correlation between survey measures and experimental measures, suggesting that the experimental measures in Uganda do a better job at mirroring women's resource control in the household. Possible reasons for this difference include implementation differences between the two experiments; in Ghana the experiment was part of a separate lab-based session with two enumerators, while in Uganda the experiment was part of the survey with one enumerator. The sample size was also different, affecting statistical power. In general, the implementation in Uganda is a more realistic setup for projects with limited resources that wish to incorporate experimental measures into survey work. As such, the results indicating that games conducted in this way can produce useful data are encouraging for researchers.

Contextual differences between the two samples may also play an important role in the usefulness of the experimental measures. The sample in Ghana is more rural and remote, and characterized by a reliance on

\footnotetext{
${ }^{21}$ The positive correlation between heterogeneity in preferences for resource control and domestic violence incidence, is consistent with results from other papers in the literature which find that intra-household preference heterogeneity is associated with worse household outcomes. For example, Serra-Garcia (2020) finds a positive correlation between heterogeneity in risk preferences and marital instability in a representative sample of the German population, while Schaner (2015) finds that heterogeneity in time preferences is associated with inefficient household savings decisions in Kenya.
} 
subsistence farming. There are also large differences in education, with the majority of the Ghana sample reporting that they have no formal schooling. In Uganda the households are all involved in some level of commercial farming and most have attended school. This difference means not only that the Ugandan households are somewhat more empowered overall, but they are also more familiar with money as a component of their day to day lives. Because these games focused on money, and the women in the Ghana sample may have been less accustomed to such choices, the games may have not performed as well in picking up meaningful aspects of their relationships.

\section{References}

Almas, I., Armand, A., Attanasio, O., \& Carneiro, P. (2018). Measuring and changing control: Women's empowerment and targeted transfers. The Economic Journal, 128(612), F609-F639.

Ambler, K. (2015). Don't tell on me: Experimental evidence of asymmetric information in transnational households. Journal of Development Economics, 113, 52-69.

Ambler, K., Jones, K., \& O'Sullivan, M. (2019). Empowering Women: Comparing the Impacts of Economic and Behavior Change Interventions. Working Paper.

Ambler, K., Godlonton, S., \& Recalde, M. P. (2020). Follow the leader? A field experiment on social influence. Working Paper.

Ashraf, N. (2009). Spousal control and intra-household decision making: An experimental study in the Philippines. American Economic Review, 99(4), 1245-77.

Barr, A., Dekker, M., Janssens, W., Kebede, B., \& Kramer, B. (2019). Cooperation in polygynous households. American Economic Journal: Applied Economics, 11(2), 266-83.

Bateman, I., \& Munro, A. (2005). An experiment on risky choice amongst households. The Economic Journal, 115(502), C176-C189.

Beblo, M., Beninger, D., Cochard, F., Couprie, H., \& Hopfensitz, A. (2015). Efficiency-equality trade-off within French and German couples: A comparative experimental study. Annals of Economics and Statistics/Annales d'Économie et de Statistique, 117/118, 233-252.

Buser, T., Niederle, M., \& Oosterbeek, H. (2020). Can competitiveness predict education and labor market outcomes? Evidence from incentivized choice and survey measures. Working Paper.

Carlsson, F., He, H., Martinsson, P., Qin, P., \& Sutter, M. (2012). Household decision making in rural China: Using experiments to estimate the influences of spouses. Journal of Economic Behavior \& Organization, 84(2), 525-536.

Carlsson, F., Martinsson, P., Qin, P., \& Sutter, M. (2013). The influence of spouses on household decision making under risk: An experiment in rural China. Experimental Economics, 16(3), 383-401.

Castilla, C. (2019). What's yours is mine, and what's mine is mine: Field experiment on income concealing between spouses in India. Journal of Development Economics, 137, 125-140.

Castilla, C., \& Walker, T. (2013). Is ignorance bliss? The effect of asymmetric information between spouses on intra-household allocations. American Economic Review, 103(3), 263-68.

Chiappori, P.-A., \& Mazzocco, M. (2017). Static and intertemporal household decisions. Journal of Economic Literature, 55(3), 985-1045.

Cochard, F., Couprie, H., \& Hopfensitz, A. (2016). Do spouses cooperate? An experimental investigation. Review of Economics of the Household, 14(1), 1-26. 
Dohmen, T., Falk, A., Huffman, D., Sunde, U., Schupp, J., \& Wagner, G. G. (2011). Individual risk attitudes: Measurement, determinants, and behavioral consequences. Journal of the European Economic Association, 9(3), 522-550.

Falk, A., Becker, A., Dohmen, T., Huffman, D., \& Sunde, U. (2016). The Preference Survey Module: A Validated Instrument for Measuring Risk. Working Paper.

Fiala, N. (2018). Business Is Tough, but Family Is Worse: Household Bargaining and Investment Decisions in Uganda. Working Paper.

Fiala, N., \& He, X. (2017). Unitary or noncooperative intrahousehold model? Evidence from couples in Uganda. The World Bank Economic Review, 30(1), S77-S85.

Heath, R., Hidrobo, M., \& Roy, S. (2020). Cash transfers, polygamy, and intimate partner violence: Experimental evidence from Mali. Journal of Development Economics, 143, 102410.

Hoel, J. B., Hidrobo, M., Bernard, T., \& Ashour, M. (2019). Productive inefficiency and cooperation between spouses: Evidence from dairy farming in Senegal. Working Paper.

Hoel, Jessica B. (2015). Heterogeneous households: A within-subject test of asymmetric information between spouses in Kenya. Journal of Economic Behavior \& Organization, 118, 123-135.

Holden, S. T., \& Bezu, S. (2013). Joint land certification and intra-household decision-making: Towards empowerment of wives?

Iversen, V., Jackson, C., Kebede, B., Munro, A., \& Verschoor, A. (2011). Do spouses realise cooperative gains? Experimental evidence from rural Uganda. World Development, 39(4), 569-578.

Jack, K., Jayachandran, S., \& Rao, S. (2018). Environmental externalities and free-riding in the household. National Bureau of Economic Research.

Kabeer, N. (1999). Resources, agency, achievements: Reflections on the measurement of women's empowerment. Development and Change, 30(3), 435-464.

Kebede, B., Tarazona, M., Munro, A., \& Verschoor, A. (2014). Intra-household efficiency: An experimental study from Ethiopia. Journal of African Economies, 23(1), 105-150.

Kling, J. R., Liebman, J. B., \& Katz, L. F. (2007). Experimental analysis of neighborhood effects. Econometrica, 75(1), 83-119.

Lecoutere, E., \& Jassogne, L. (2019). Fairness and efficiency in smallholder farming: The relation with intrahousehold decision-making. The Journal of Development Studies, 55(1), 57-82.

Lenjiso, B. M., Smits, J., \& Ruben, R. (2016). Transforming gender relations through the market: Smallholder milk market participation and womens intra-household bargaining power in Ethiopia. The Journal of Development Studies, 52(7), 1002-1018.

Lopez, M. C., Munro, A., \& Tarazona-Gomez, M. (2015). Us and Them: Experimental evidence on what creates efficiency in choices made by married couples. Tokyo, National Graduate Institute for Policy Studies, GRIPS Discussion Paper, 15-10.

Lowes, S. (2018). Matrilineal kinship and spousal cooperation: Evidence from the matrilineal belt. Working Paper.

Mani, A. (2020). Mine, yours or ours? The efficiency of household investment decisions: An experimental approach. The World Bank Economic Review, 34(3), 575-596.

Munro, A. (2018). Intra-Household Experiments: A Survey. Journal of Economic Surveys, 32(1), 134-175.

Munro, A., Kebede, B., Tarazona, M., \& Verschoor, A. (2019). The lion's share: An experimental analysis of polygamy in northern Nigeria. Economic Development and Cultural Change, 67(4), 833-861. 
Munro, A., Kebede, B., Tarazona-Gomez, M., \& Verschoor, A. (2014). Autonomy and efficiency. An experiment on household decisions in two regions of India. Journal of the Japanese and International Economies, 33, 114-133.

Peters, H. E., Ünür, A. S., Clark, J., \& Schulze, W. D. (2004). Free-riding and the provision of public goods in the family: A laboratory experiment. International Economic Review, 45(1), 283-299.

Roy, S., Hidrobo, M., Hoddinott, J., Koch, B., \& Ahmed, A. (2019). Can transfers and behavior change communication reduce intimate partner violence four years post-program? Experimental evidence from Bangladesh. IFPRI Discussion Paper, 1869.

Schaner, S. (2015). Do opposites detract? Intrahousehold preference heterogeneity and inefficient strategic savings. American Economic Journal: Applied Economics, 7(2), 135-74.

Schaner, S. (2017). The cost of convenience? Transaction costs, bargaining power, and savings account use in Kenya. Journal of Human Resources, 52(4), 919-945.

Serra-Garcia, M. (2020). Risk Attitudes and Conflict in the Household.

Vieider, F. M., Lefebvre, M., Bouchouicha, R., Chmura, T., Hakimov, R., Krawczyk, M., \& Martinsson, P. (2015). Common components of risk and uncertainty attitudes across contexts and domains: Evidence from 30 countries. Journal of the European Economic Association, 13(3), 421-452. 
Figure 1. Willingness to pay for resource control, Task 1

(a) Ghana

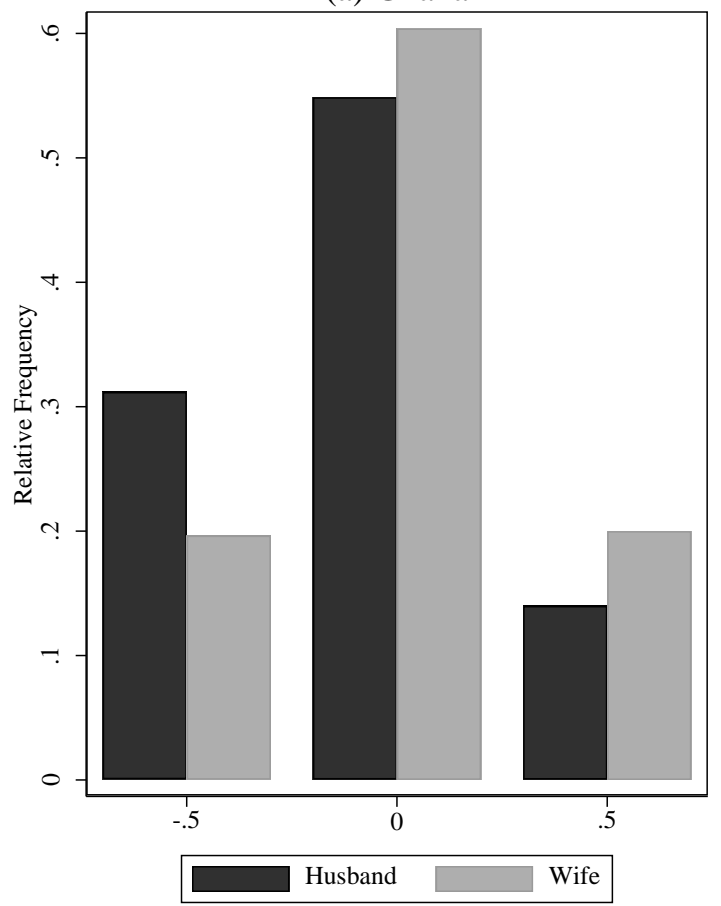

(b) Uganda

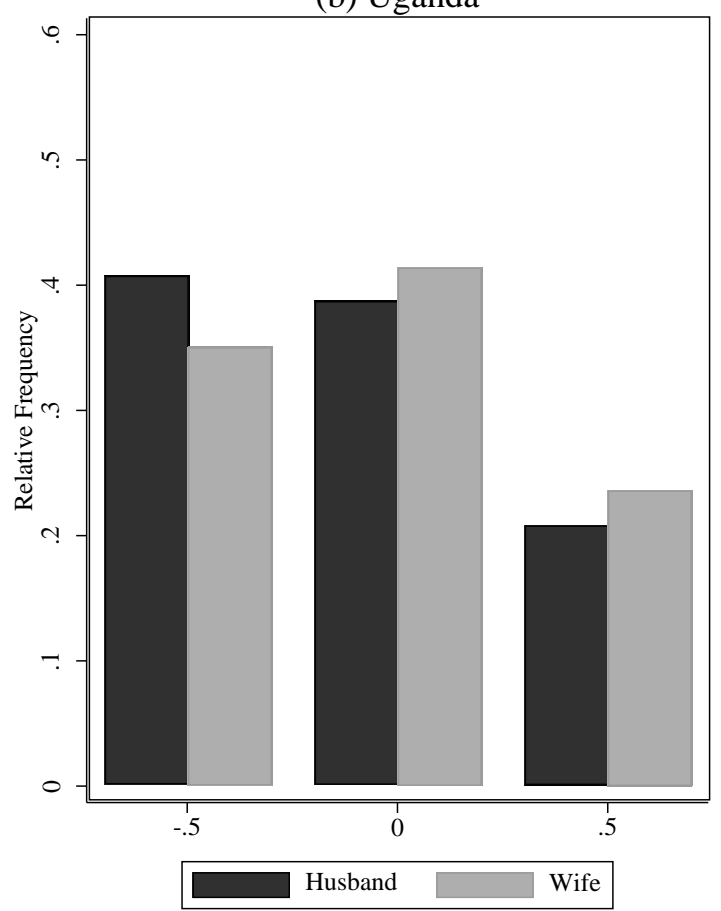

Notes: Willingness to pay acquires a value $v \in\{-0.5,0,0.5\}$ when the spouse is willing to sacrifice $v$ (as a share of the endowment) to receive the money. A positive (negative) value indicates willingness to pay to receive (not receive) the money. The distributions are significantly different between husbands and wives in both panels (Chi-squared $\mathrm{p}<0.001$ ). 
Figure 2. Dictator game decisions, Task 2

(a) Ghana

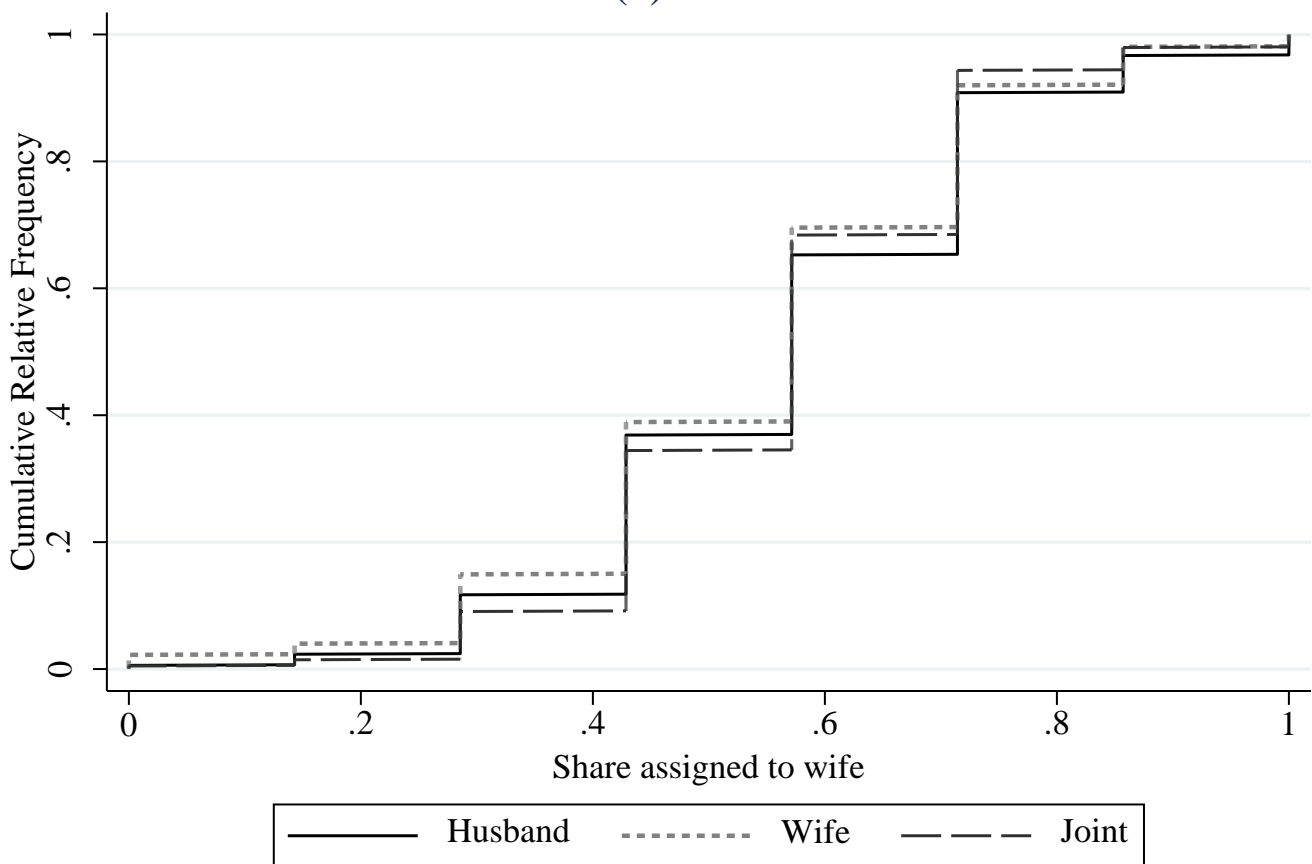

(b) Uganda

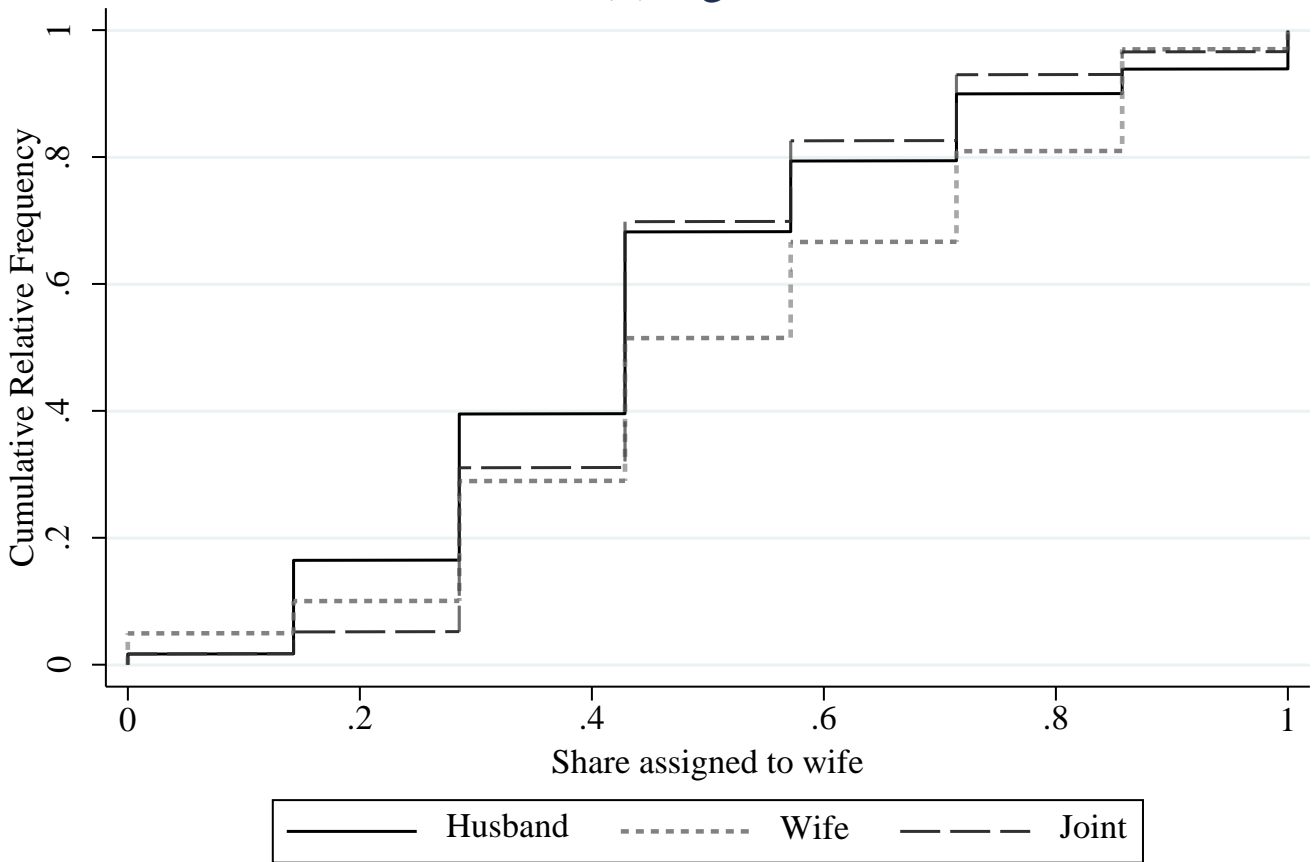

Note: Husband and Wife indicate the private decisions made by spouses. Joint inidicates the decision made jointly by the couple, after they make private decisions. 
Figure 3. Intra-household differences in dictator game decisions, Task 2

(a) Ghana

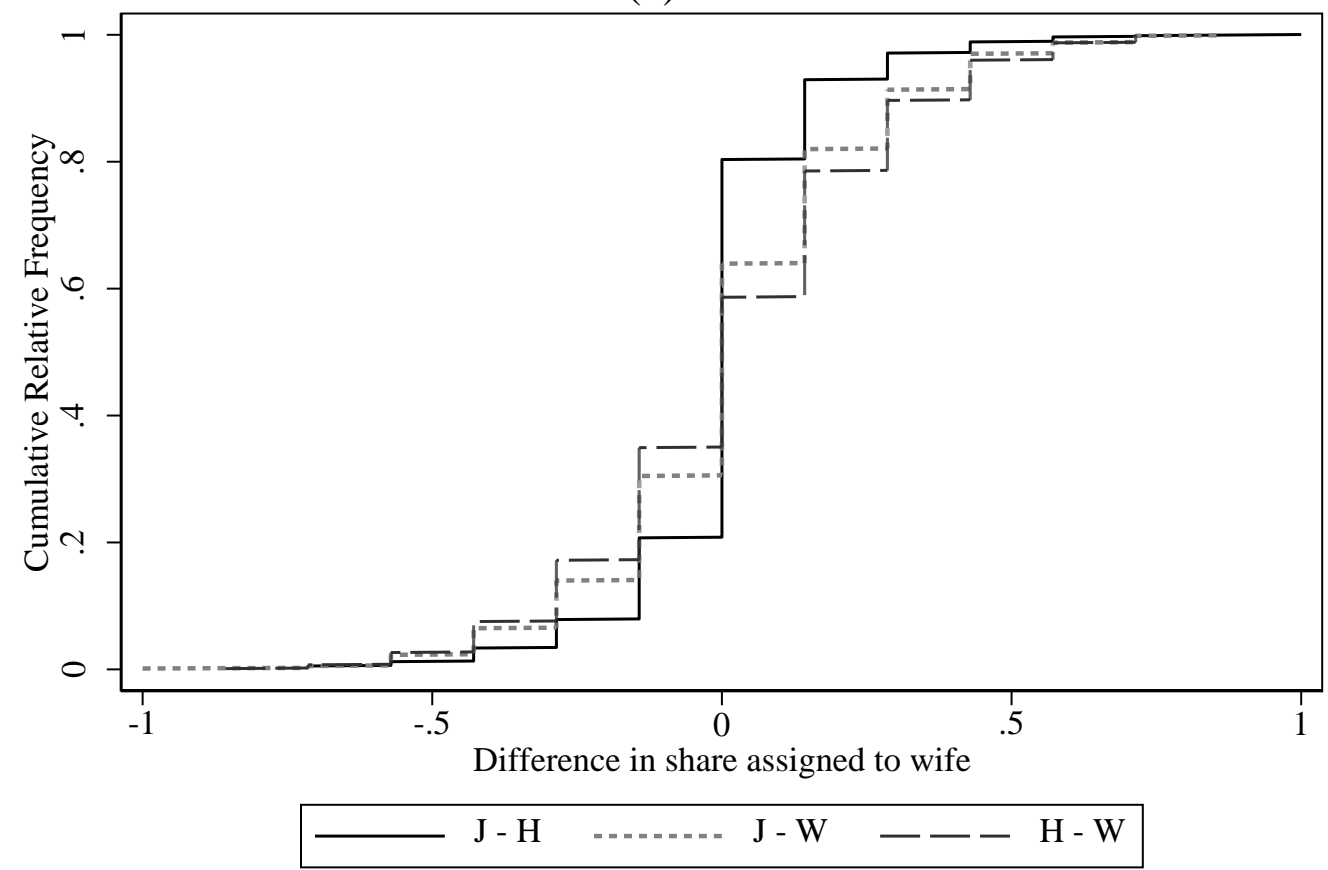

(b) Uganda

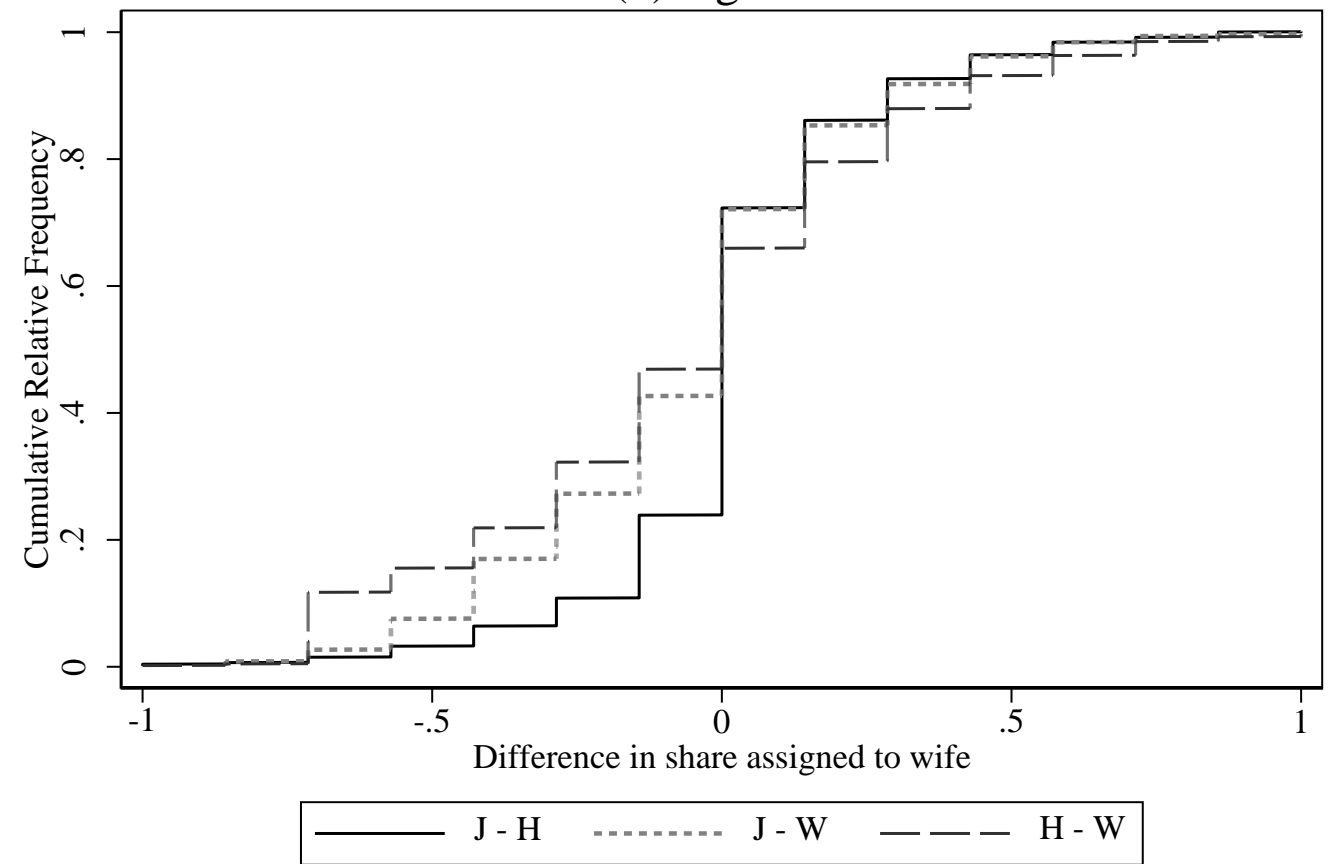

Note: J, H, and W denote the joint, husband, and wife decisions respectively (shown in Figure 2). J-H and J-W denote the difference between the joint decision made by the couple and the private decision made by the husband and the wife respectively. $\mathrm{H}-\mathrm{W}$ is the difference between the private decisions made by spouses. 
Table 1: Summary Statistics

\begin{tabular}{lcc}
\hline \hline & Ghana & Uganda \\
Household size & 9.12 & 8.70 \\
Polygamous household & 0.33 & 0.34 \\
Years of marriage & 21.68 & 19.54 \\
Age of wife & 39.03 & 38.31 \\
Wife education & & \\
$\quad$ None & 0.78 & 0.18 \\
$\quad$ Incomplete primary & 0.14 & 0.38 \\
$\quad$ Complete primary + & 0.08 & 0.44 \\
Age of husband & 48.58 & 46.60 \\
Husband education & & \\
$\quad$ None & 0.59 & 0.06 \\
$\quad$ Incomplete primary & 0.22 & 0.34 \\
$\quad$ Complete primary + & 0.19 & 0.60 \\
\hline \hline Note: Length of marriage is measured in years. There are 1,025 \\
households in the Ghana sample and 2,363 households in the \\
Uganda sample.
\end{tabular}


Table 2: Fixed Effects Regressions to Estimate Difference between Husband and Wife
(1)
(3)
(4)
(5)
(6)
(7)
(8)

Willing to pay

Dictator game

To control resources To have spouse control Percentage assigned to Absolute distance to joint resources wife |J-I|

\section{Panel A: Ghana}

\begin{tabular}{|c|c|c|c|c|c|c|c|c|}
\hline Cofficient on "Wife" & $0.0595 * *$ & $0.0520^{*}$ & $-0.115^{* * *}$ & $-0.0946 * * *$ & $-0.0220^{*}$ & -0.0204 & $0.0800 * * *$ & $0.0782 * * *$ \\
\hline Standard error & {$[0.0232]$} & {$[0.0310]$} & [0.0264] & [0.0365] & {$[0.0117]$} & [0.0155] & {$[0.00966]$} & [0.0129] \\
\hline R squared & 0.514 & 0.517 & 0.531 & 0.536 & 0.505 & 0.506 & 0.560 & 0.565 \\
\hline $\mathrm{N}$ & 2050 & 2050 & 2050 & 2050 & 2050 & 2050 & 2050 & 2050 \\
\hline Mean outcome: husbands & \multicolumn{2}{|c|}{0.14} & \multicolumn{2}{|c|}{0.311} & \multicolumn{2}{|c|}{0.565} & \multicolumn{2}{|c|}{0.093} \\
\hline
\end{tabular}

Mean outcome: husbands

0.14

\begin{tabular}{lcccccccc}
\hline Cofficient on "Wife" & $0.0288^{*}$ & 0.0317 & $-0.0563^{* * *}$ & $-0.0851^{* * *}$ & $0.0704^{* * *}$ & $0.0796^{* * *}$ & $0.0759^{* * *}$ & $0.0633^{* * *}$ \\
Standard error & {$[0.0158]$} & {$[0.0253]$} & {$[0.0185]$} & {$[0.0289]$} & {$[0.0111]$} & {$[0.0179]$} & {$[0.00846]$} & {$[0.0141]$} \\
R squared & 0.573 & 0.576 & 0.570 & 0.573 & 0.416 & 0.421 & 0.509 & 0.513 \\
$\mathrm{~N}$ & 4726 & 4726 & 4726 & 4726 & 4726 & 4726 & 4726 & 4726 \\
Mean outcome: husbands & \multicolumn{2}{c}{0.207} & \multicolumn{2}{c}{0.406} & & 0.444 & & 0.145
\end{tabular}

Panel B: Uganda

\begin{tabular}{llllllll} 
Control variables & No & Yes & No & Yes & No & Yes & No \\
\hline
\end{tabular}

Note: J indicates joint allocation to wife, I indicates individual allocation to wife. Responses are at the individual level and include a fixed effect for household, as well as controls for age group, schooling, personal income, and personal savings. Standard errors are clustered at the household level. 
Table 3: Relationship between Experimental Measures, Wife Responses

(1)

(2)

(3)

(4)

(5)

(6)

(7)

(8)

Dependent variable is

Willing to pay to control resources

Willing to pay to have spouse control resources

\section{Panel A: Ghana}

Percent of endowment assigned to wife: wife

$\begin{array}{cccc}0.437^{\star \star \star} & 0.438^{\star \star \star} & -0.418^{\star \star \star} & -0.424^{\star \star \star} \\ (0.063) & (0.063) & (0.066) & (0.065) \\ & 0.059 & & -0.115 \\ & (0.078) & & (0.081) \\ & -0.026 & & 0.132 \\ & (0.089) & & (0.097)\end{array}$

Percent of endowment assigned to wife: husband

$0.187^{* *}$

$-0.021$

(0.086)

(0.076)

allocation to wife

Absolute difference: Husband allocation to wife -

wife allocation to wife

R-squared

0.079

$0.170^{* *}$

$-0.028$

Number of observations

1,025

0.079

0.054

(0.082)

Panel B: Uganda

Percent of endowment assigned to wife: wife

$0.244^{\star * *}$

1,025

1,025

0.052

1,025

0.065

1,025

0.068

$(0.074)$

(0.033)

$0.235^{\star \star \star}$
$(0.035)$
-0.000
$(0.040)$
0.095
$(0.047)$

$-0.406^{\star * *}$

1,025

0.036

0.034

Percent of endowment assigned to wife: husband

$-0.000$

(0.038)

$-0.400^{\star * *}$

$-0.400^{\star \star *}$

$-0.007$

$(0.045)$

0.095

$-0.073$

Percent of endowment assigned to wife: joint

$(0.047)$

(0.054)

Absolute difference: Joint allocation to wife - wife allocation to wife

$0.054^{* *}$

(0.042)

$0.055^{\star *}$

(0.035)

wife allocation to wife

R-squared

0.041

0.043

0.023

0.026

2,363

2,363

$2,363 \quad 2,363$

from the $n$

Note: Unless otherwise indicated, responses are from the wife. Dependent variables are from the willingness to pay to control resources task. Independent variables are from the dictator game task. All regressions include the following household level control variables: food security measure, wealth measure, household income, and household savings. They also include the following individual level control variables: age group, schooling, individual income, and individual savings. Robust standard errors are in parentheses. 
Table 4: Correlation of Experimental Measures with Survey Measures: Ghana, Wife Responses

\begin{tabular}{|c|c|c|c|c|c|}
\hline & $\begin{array}{l}\text { Agreement } \\
\text { index }\end{array}$ & $\begin{array}{l}\text { Psychological } \\
\text { violence } \\
\text { incidence } \\
\text { index }\end{array}$ & $\begin{array}{l}\text { Physical } \\
\text { violence } \\
\text { incidence } \\
\text { index }\end{array}$ & $\begin{array}{l}\text { Wife's access } \\
\text { to resources } \\
\text { index }\end{array}$ & $\begin{array}{c}\text { Decision } \\
\text { making index }\end{array}$ \\
\hline \multicolumn{6}{|l|}{ Panel A: Model 1} \\
\hline \multirow[t]{2}{*}{ Willing to pay to control resources } & 0.052 & -0.026 & -0.019 & 0.080 & 0.110 \\
\hline & $(0.076)$ & $(0.081)$ & $(0.093)$ & $(0.080)$ & $(0.084)$ \\
\hline \multirow[t]{2}{*}{ Willing to pay to have spouse control resources } & -0.062 & $-0.135^{*}$ & 0.093 & 0.041 & 0.095 \\
\hline & $(0.074)$ & $(0.078)$ & $(0.108)$ & $(0.079)$ & $(0.084)$ \\
\hline R2 & 0.018 & 0.041 & 0.035 & 0.054 & 0.021 \\
\hline \multicolumn{6}{|l|}{ Panel B: Model 2} \\
\hline \multirow[t]{2}{*}{ Percent of endowment assigned to wife: wife } & 0.024 & $0.532 * * *$ & -0.009 & 0.167 & -0.195 \\
\hline & $(0.189)$ & $(0.177)$ & $(0.116)$ & $(0.159)$ & $(0.180)$ \\
\hline \multirow[t]{2}{*}{ Percent of endowment assigned to wife: husband } & -0.303 & 0.050 & -0.151 & 0.102 & 0.239 \\
\hline & $(0.276)$ & $(0.202)$ & $(0.148)$ & $(0.193)$ & $(0.200)$ \\
\hline \multirow[t]{2}{*}{ Percent of endowment assigned to wife: joint } & 0.165 & $-0.483 *$ & 0.105 & 0.083 & 0.068 \\
\hline & $(0.336)$ & $(0.253)$ & $(0.257)$ & $(0.219)$ & $(0.222)$ \\
\hline R2 & 0.019 & 0.053 & 0.034 & 0.055 & 0.022 \\
\hline \multicolumn{6}{|l|}{ Panel C: Model 3} \\
\hline Absolute difference: Joint allocation to wife - wife & 0.154 & 0.354 & -0.038 & -0.016 & -0.023 \\
\hline allocation to wife & $(0.235)$ & $(0.227)$ & $(0.127)$ & $(0.189)$ & $(0.193)$ \\
\hline $\mathrm{R} 2$ & 0.017 & 0.047 & 0.033 & 0.054 & 0.022 \\
\hline \multicolumn{6}{|l|}{ Panel D: Model 4} \\
\hline Absolute difference: Husband allocation to wife - & -0.158 & -0.013 & -0.269 & 0.059 & -0.073 \\
\hline wife allocation to wife & $(0.160)$ & $(0.191)$ & $(0.174)$ & $(0.192)$ & $(0.195)$ \\
\hline $\mathrm{R} 2$ & 0.017 & 0.040 & 0.035 & 0.054 & 0.020 \\
\hline Number of observations & 1,025 & 1,025 & 1,025 & 1,025 & 1,025 \\
\hline
\end{tabular}


Table 5: Correlation of Experimental Measures with Survey Measures: Uganda, Wife Responses

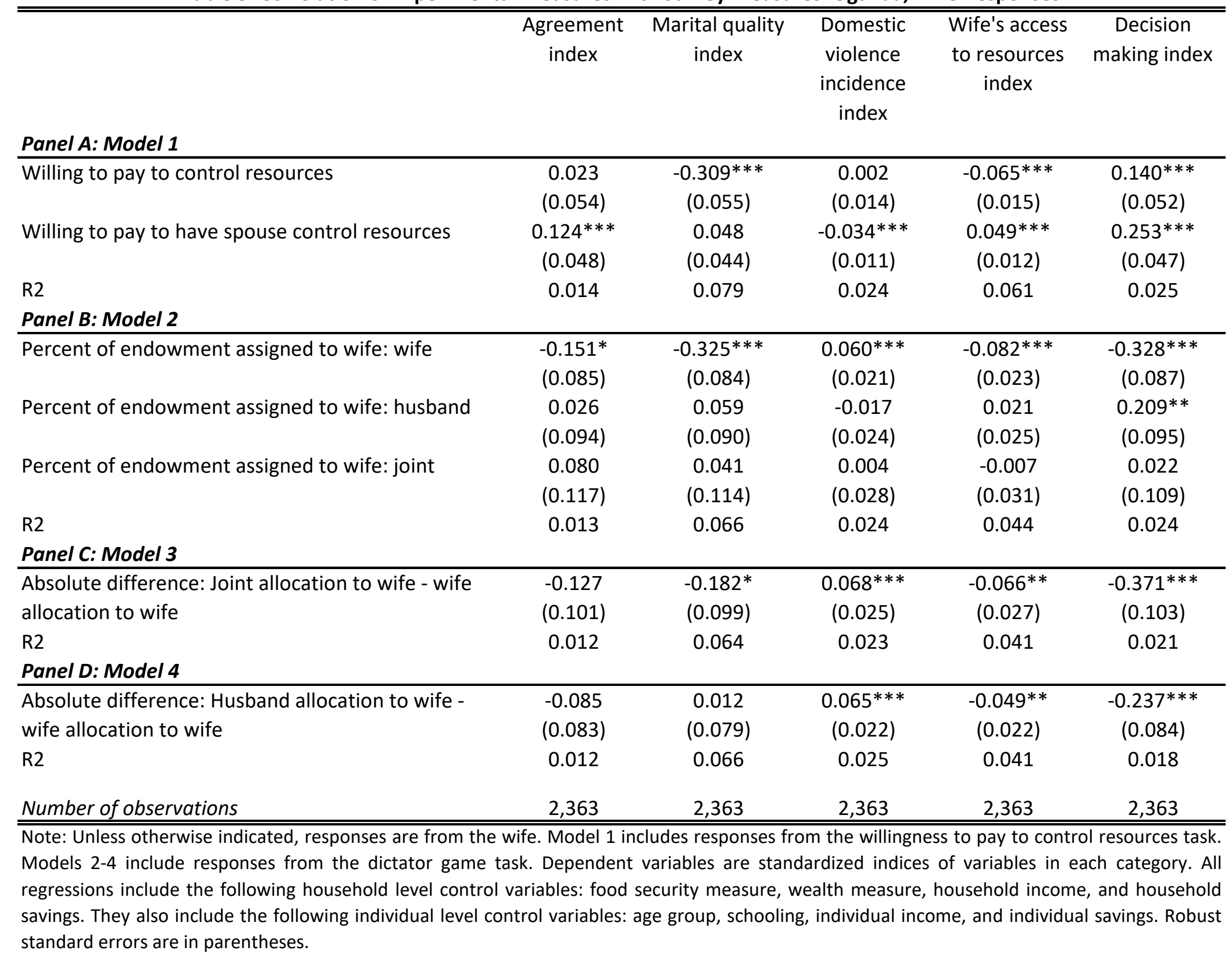


Dependent variable is

Willing to pay to control resources Willing to pay to have spouse control resources

\section{Panel A: Ghana}

Percent of endowment assigned to wife: wife

$-0.309 * * *$

$-0.155^{* *}$

$0.447^{* * *} \quad 0.354^{* * *}$

(0.062)

(0.073)

0.050

$(0.077) \quad(0.091)$

Percent of endowment assigned to wife: husband

(0.064)

0.078

$-0.343^{* * *}$

(0.071)

Percent of endowment assigned to wife: joint

(0.078)

$0.206^{*}$

(0.105)

Absolute difference: Joint allocation to wife -

husband allocation to wife

\begin{tabular}{|c|c|c|c|c|c|c|c|}
\hline & & $\begin{array}{c}0.054 \\
(0.095)\end{array}$ & & & & $\begin{array}{c}0.103 \\
(0.116)\end{array}$ & \\
\hline & & & $0.144^{*}$ & & & & $-0.145^{*}$ \\
\hline & & & $(0.074)$ & & & & $(0.082)$ \\
\hline 0.065 & 0.083 & 0.039 & 0.053 & 0.075 & 0.080 & 0.049 & 0.054 \\
\hline 1,025 & 1,025 & 1,025 & 1,025 & 1,025 & 1,025 & 1,025 & 1,025 \\
\hline $0.286 * * *$ & $-0.251 * * *$ & & & $0.526 * * *$ & $0.397^{* * *}$ & & \\
\hline$(0.030)$ & $(0.035)$ & & & (0.041) & $(0.047)$ & & \\
\hline & $-0.121 * * *$ & & & & -0.023 & & \\
\hline & (0.034) & & & & $(0.041)$ & & \\
\hline & $-0.183 * * *$ & & & & $0.384^{* * *}$ & & \\
\hline & $(0.040)$ & & & & $(0.057)$ & & \\
\hline & & $-0.184 * * *$ & & & & $0.339 * * *$ & \\
\hline & & $(0.042)$ & & & & (0.059) & \\
\hline & & & $\begin{array}{r}-0.105^{* * *} \\
(0.033)\end{array}$ & & & & $\begin{array}{r}0.115^{* * *} \\
(0.040)\end{array}$ \\
\hline 0.048 & 0.063 & 0.029 & 0.034 & 0.079 & 0.099 & 0.035 & 0.056 \\
\hline 2,363 & 2,363 & 2,363 & 2,363 & 2,363 & 2,363 & 2,363 & 2,363 \\
\hline
\end{tabular}

Absolute difference: Husband allocation to wife -

wife allocation to wife

R-squared

Number of observations

0.065

0.083

0.039

0.075

$0.082)$

Panel B: Uganda

Percent of endowment assigned to wife: wife

Percent of endowment assigned to wife: husband

$(0.047)$

$-0.023$

Percent of endowment assigned to wife: joint

Absolute difference: Joint allocation to wife -

husband allocation to wife

Absolute difference: Husband allocation to wife -

wife allocation to wife

R-squared

ins

2,363

2,363

2,363

2,363

Note: Unless otherwise indicated, responses are from the husband. Dependent variables are from the willingness to pay to control resources task. Independent variables are from the dictator game task. All regressions include the following household level control variables: food security measure, wealth measure, household income, and household savings. They also include the following individual level control variables: age group, schooling, individual income, and individual savings. Robust standard errors are in parentheses. 
Appendix Table 2: Survey Measures Index Components, Ghana

\begin{tabular}{|c|c|c|c|c|}
\hline & Mean & SD & Min & Max \\
\hline \multicolumn{5}{|c|}{ Agreement: Wife reports couple agrees on (1 -5 scale, 5 is agree) } \\
\hline Spending & 1.462 & 0.746 & 1 & 5 \\
\hline Saving/Investing & 1.412 & 0.696 & 1 & 5 \\
\hline Crop choice & 1.443 & 0.675 & 1 & 5 \\
\hline Land use & 1.385 & 0.672 & 1 & 5 \\
\hline \multicolumn{5}{|c|}{ Domestic violence: Psychological (behavior ever occurred?) } \\
\hline \# of types of controlling behavior (of 7) & 1.188 & 1.320 & 0 & 7 \\
\hline \# of types of emotional abuse (of 3 ) & 0.539 & 0.806 & 0 & 3 \\
\hline Reports any of these & 0.710 & 0.454 & 0 & 1 \\
\hline \multicolumn{5}{|c|}{ Domestic violence: Physical (behavior ever occurred?) } \\
\hline Pushing/shaking/throwing things & 0.037 & 0.189 & 0 & 1 \\
\hline Slapping & 0.011 & 0.106 & 0 & 1 \\
\hline Twisting arm / pulling hair & 0.024 & 0.152 & 0 & 1 \\
\hline Punching & 0.061 & 0.239 & 0 & 1 \\
\hline Kicking/dragging/beating & 0.180 & 0.385 & 0 & 1 \\
\hline Choking/burning & 0.041 & 0.198 & 0 & 1 \\
\hline Threatening with weapon & 0.084 & 0.277 & 0 & 1 \\
\hline Reports any of these & 0.209 & 0.407 & 0 & 1 \\
\hline \multicolumn{5}{|l|}{ Wife's access to resources } \\
\hline Wife owns house & 0.309 & 0.462 & 0 & 1 \\
\hline Wife owns land & 0.312 & 0.464 & 0 & 1 \\
\hline Wife earns as much or more than husband & 0.149 & 0.356 & 0 & 1 \\
\hline Personal expenditure ratio (Wife/Husband) & 0.440 & 0.280 & 0 & 1 \\
\hline \multicolumn{5}{|l|}{ Decision making: Wife has equal or more say on... } \\
\hline Use of own earnings & 0.802 & 0.398 & 0 & 1 \\
\hline Use of husband earnings & 0.589 & 0.492 & 0 & 1 \\
\hline Own healthcare & 0.646 & 0.479 & 0 & 1 \\
\hline Major purchases & 0.604 & 0.489 & 0 & 1 \\
\hline Visits to own family & 0.700 & 0.459 & 0 & 1 \\
\hline Investment in business vs family & 0.794 & 0.405 & 0 & 1 \\
\hline
\end{tabular}

Note: There are 1,025 households in this sample. 
Appendix Table 3: Survey Measures Index Components, Uganda

\begin{tabular}{|c|c|c|c|c|}
\hline & Mean & SD & Min & Max \\
\hline \multicolumn{5}{|l|}{ Agreement: Husband and Wife agree on } \\
\hline Spending on clothes vs. entertainment & 0.693 & 0.461 & 0 & 1 \\
\hline Spending on education vs. health & 0.767 & 0.423 & 0 & 1 \\
\hline Spending on business/farm vs. house quality & 0.616 & 0.486 & 0 & 1 \\
\hline How to use land & 0.450 & 0.498 & 0 & 1 \\
\hline \multicolumn{5}{|l|}{ Marital quality: Wife's report (1 - 10 scale, 10 is agree) } \\
\hline We discuss $\mathrm{HH}$ decisions/issues together & 7.986 & 2.467 & 1 & 10 \\
\hline $\mathrm{H}$ contributes a lot to $\mathrm{HH}$ wellbeing & 8.202 & 2.374 & 1 & 10 \\
\hline We have talked about how to improve family situation & 8.084 & 2.412 & 1 & 10 \\
\hline I like to discuss personal concerns with $\mathrm{H}$ & 7.259 & 2.787 & 1 & 10 \\
\hline I have confidence in the stability of our relationship & 7.959 & 2.628 & 1 & 10 \\
\hline I strongly desire to promote the wellbeing of $\mathrm{H}$ & 8.703 & 2.106 & 1 & 10 \\
\hline \multicolumn{5}{|l|}{ Domestic violence: Hit/pushed/slapped/thrown things? } \\
\hline Wife report: Ever & 0.182 & 0.386 & 0 & 1 \\
\hline Wife report: In past year & 0.092 & 0.289 & 0 & 1 \\
\hline Husband report: In past year & 0.073 & 0.260 & 0 & 1 \\
\hline \multicolumn{5}{|l|}{ Wife's access to resources } \\
\hline Personal expenditures ratio (Wife/Husband) & 0.426 & 0.334 & 0 & 1 \\
\hline Wife reports having any say in use of cane income & 0.776 & 0.417 & 0 & 1 \\
\hline \multicolumn{5}{|l|}{ Decision making: Wife has equal or more say on... } \\
\hline Use of own earnings & 0.460 & 0.499 & 0 & 1 \\
\hline Use of husband earnings & 0.432 & 0.495 & 0 & 1 \\
\hline Own healthcare & 0.761 & 0.426 & 0 & 1 \\
\hline Children's healthcare & 0.746 & 0.436 & 0 & 1 \\
\hline Major purchases & 0.508 & 0.500 & 0 & 1 \\
\hline Minor purchases & 0.658 & 0.474 & 0 & 1 \\
\hline Visits to own family & 0.666 & 0.472 & 0 & 1 \\
\hline
\end{tabular}

Note: There are 2,363 households in this sample. 
Appendix Table 4: Correlation of Experimental Measures with Survey Measures: Ghana, Husband Responses

\begin{tabular}{|c|c|c|c|c|c|}
\hline & $\begin{array}{l}\text { Agreement } \\
\text { index }\end{array}$ & $\begin{array}{l}\text { Psychological } \\
\text { violence } \\
\text { incidence } \\
\text { index }\end{array}$ & $\begin{array}{l}\text { Physical } \\
\text { violence } \\
\text { incidence } \\
\text { index }\end{array}$ & $\begin{array}{l}\text { Wife's access } \\
\text { to resources } \\
\text { index }\end{array}$ & $\begin{array}{c}\text { Decision } \\
\text { making index }\end{array}$ \\
\hline \multicolumn{6}{|l|}{ Panel A: Model 1} \\
\hline \multirow[t]{2}{*}{ Willing to pay to control resources } & 0.070 & 0.073 & -0.071 & 0.070 & $-0.263 * * *$ \\
\hline & $(0.108)$ & $(0.090)$ & $(0.080)$ & $(0.095)$ & $(0.100)$ \\
\hline \multirow[t]{2}{*}{ Willing to pay to have spouse control resources } & 0.003 & 0.043 & 0.055 & 0.020 & $-0.119 *$ \\
\hline & $(0.074)$ & $(0.075)$ & $(0.076)$ & $(0.069)$ & $(0.069)$ \\
\hline R2 & 0.018 & 0.037 & 0.033 & 0.050 & 0.024 \\
\hline \multicolumn{6}{|l|}{ Panel B: Model 2} \\
\hline \multirow[t]{2}{*}{ Percent of endowment assigned to wife: wife } & -0.114 & $0.508 * * *$ & -0.036 & 0.139 & -0.229 \\
\hline & $(0.198)$ & $(0.173)$ & $(0.113)$ & $(0.160)$ & $(0.172)$ \\
\hline \multirow[t]{2}{*}{ Percent of endowment assigned to wife: husband } & -0.013 & 0.039 & -0.159 & 0.107 & 0.094 \\
\hline & $(0.172)$ & $(0.203)$ & $(0.149)$ & $(0.193)$ & $(0.201)$ \\
\hline \multirow[t]{2}{*}{ Percent of endowment assigned to wife: joint } & -0.139 & $-0.486^{*}$ & 0.107 & 0.086 & 0.346 \\
\hline & $(0.215)$ & $(0.257)$ & $(0.246)$ & $(0.221)$ & $(0.230)$ \\
\hline $\mathrm{R} 2$ & 0.019 & 0.050 & 0.032 & 0.051 & 0.021 \\
\hline \multicolumn{6}{|l|}{ Panel C: Model 3} \\
\hline Absolute difference: Joint allocation to wife - & -0.170 & 0.140 & -0.169 & 0.195 & $-0.475^{* *}$ \\
\hline husband allocation to wife & $(0.224)$ & $(0.299)$ & $(0.189)$ & $(0.237)$ & $(0.230)$ \\
\hline $\mathrm{R} 2$ & 0.018 & 0.036 & 0.034 & 0.050 & 0.019 \\
\hline \multicolumn{6}{|l|}{ Panel D: Model 4} \\
\hline Absolute difference: Husband allocation to wife - & $-0.338^{*}$ & 0.019 & -0.272 & 0.021 & -0.081 \\
\hline wife allocation to wife & $(0.186)$ & $(0.188)$ & $(0.177)$ & $(0.192)$ & $(0.201)$ \\
\hline $\mathrm{R} 2$ & 0.021 & 0.037 & 0.034 & 0.050 & 0.018 \\
\hline Number of observations & 1,025 & 1,025 & 1,025 & 1,025 & 1,025 \\
\hline \multicolumn{6}{|c|}{$\begin{array}{l}\text { Note: Unless otherwise indicated, responses are from the husband. Model } 1 \text { includes responses from the willingness to pay to control resources } \\
\text { task. Models 2-4 include responses from the dictator game task. Dependent variables are standardized indices of variables in each category. Wife } \\
\text { responses are used to construct the indices on psychological and physicial violence as well as wife's access to resources. All regressions include the } \\
\text { following household level control variables: food security measure, wealth measure, household income, and household savings. They also include } \\
\text { the following individual level control variables: age group, schooling, individual income, and individual savings. Robust standard errors are in } \\
\text { parentheses. }\end{array}$} \\
\hline
\end{tabular}


Appendix Table 5: Correlation of Experimental Measures with Survey Measures: Uganda, Husband Responses

\begin{tabular}{|c|c|c|c|c|c|}
\hline & $\begin{array}{l}\text { Agreement } \\
\text { index }\end{array}$ & $\begin{array}{c}\text { Marital quality } \\
\text { index }\end{array}$ & $\begin{array}{l}\text { Domestic } \\
\text { violence } \\
\text { incidence } \\
\text { index }\end{array}$ & $\begin{array}{l}\text { Wife's access } \\
\text { to resources } \\
\text { index }\end{array}$ & $\begin{array}{c}\text { Decision } \\
\text { making index }\end{array}$ \\
\hline \multicolumn{6}{|l|}{ Panel A: Model 1} \\
\hline \multirow[t]{2}{*}{ Willing to pay to control resources } & 0.048 & $-0.118^{* *}$ & 0.005 & 0.017 & $-0.092^{*}$ \\
\hline & $(0.056)$ & $(0.060)$ & $(0.015)$ & $(0.016)$ & $(0.055)$ \\
\hline \multirow[t]{2}{*}{ Willing to pay to have spouse control resources } & 0.033 & -0.044 & $-0.022^{* *}$ & $0.031 * *$ & $0.194 * * *$ \\
\hline & $(0.047)$ & $(0.044)$ & $(0.011)$ & $(0.013)$ & $(0.046)$ \\
\hline $\mathrm{R} 2$ & 0.012 & 0.034 & 0.024 & 0.037 & 0.034 \\
\hline \multicolumn{6}{|l|}{ Panel B: Model 2} \\
\hline \multirow[t]{2}{*}{ Percent of endowment assigned to wife: wife } & $-0.160 *$ & -0.067 & $0.058 * * *$ & $-0.087 * * *$ & -0.058 \\
\hline & $(0.086)$ & $(0.087)$ & $(0.021)$ & $(0.023)$ & $(0.088)$ \\
\hline \multirow[t]{2}{*}{ Percent of endowment assigned to wife: husband } & 0.018 & $0.167 *$ & -0.014 & 0.021 & 0.009 \\
\hline & $(0.094)$ & $(0.091)$ & $(0.024)$ & $(0.025)$ & $(0.095)$ \\
\hline \multirow[t]{2}{*}{ Percent of endowment assigned to wife: joint } & 0.081 & $0.193 *$ & 0.007 & -0.007 & $0.177^{*}$ \\
\hline & $(0.117)$ & $(0.108)$ & $(0.028)$ & $(0.031)$ & $(0.106)$ \\
\hline $\mathrm{R} 2$ & 0.014 & 0.037 & 0.025 & 0.042 & 0.023 \\
\hline \multicolumn{6}{|l|}{ Panel C: Model 3} \\
\hline Absolute difference: Joint allocation to wife - & 0.139 & 0.143 & 0.007 & $0.069 * *$ & $0.198^{*}$ \\
\hline husband allocation to wife & $(0.114)$ & $(0.112)$ & $(0.029)$ & $(0.030)$ & $(0.106)$ \\
\hline $\mathrm{R} 2$ & 0.012 & 0.034 & 0.025 & 0.039 & 0.024 \\
\hline \multicolumn{6}{|l|}{ Panel D: Model 4} \\
\hline Absolute difference: Husband allocation to wife - & -0.090 & 0.011 & $0.071 * * *$ & $-0.046 * *$ & 0.070 \\
\hline wife allocation to wife & $(0.083)$ & $(0.085)$ & $(0.022)$ & $(0.022)$ & $(0.099)$ \\
\hline $\mathrm{R} 2$ & 0.012 & 0.036 & 0.028 & 0.039 & 0.022 \\
\hline Number of observations & 2,363 & 2,363 & 2,363 & 2,363 & 2,363 \\
\hline \multicolumn{6}{|c|}{$\begin{array}{l}\text { Note: Unless otherwise indicated, responses are from the husband. Model } 1 \text { includes responses from the willingness to pay to control resources } \\
\text { task. Models 2-4 include responses from the dictator game task. Dependent variables are standardized indices of variables in each category. } \\
\text { Wife responses are used to construct the indices on agreement, domestic violence, and wife's access to resources. All regressions include the } \\
\text { following household level control variables: food security measure, wealth measure, household income, and household savings. They also } \\
\text { include the following individual level control variables: age group, schooling, individual income, and individual savings. Robust standard errors } \\
\text { are in parentheses. }\end{array}$} \\
\hline
\end{tabular}




\section{Appendix A. The Ghana Experiment}

\section{A1. Experimental procedures}

All spouses who expressed interest in being part of the randomized control trial conducted by a local agribusiness were invited to participate a "meeting”. This meeting was the lab experiment were incentivized decisions were elicited. Invitations were made in person by an enumerator 1 or 2 days before the date of the session. Spouses were informed at the time of invitation that they could earn money by attending the meeting, and that the two spouses invited had to be the ones attending to be able to participate. A minimum show-up fee of 3 GHC (\$0.78USD) was guaranteed for each person for attending the meeting.

Meetings were conducted in a central location in each village. Various sessions were administered in a village if necessary at different times. Upon arrival to a session, participants were asked to wait to be privately interviewed. The waiting area was separate from the interview area, and from the payment area. We prevented communication between participants waiting to be interviewed and those who already participated in the one on one interview.

Private decisions were elicited from both spouses by two enumerators who privately interviewed spouses at the same time. Each interview was conducted in a separate interview booth that ensured privacy. Twelve enumerators simultaneously conducted interviews in each "meeting". Enumerators were matched in pairs for the duration of data collection and were randomly assigned to couples in each village. Which enumerator interviewed the husband or the wife was rotated within each enumerator pair. We had a total of 3 female and 9 male enumerators eliciting incentivized decisions in the lab-in-the-field experiment. A complete interview with two spouses took approximately 30 minutes to complete.

\section{A.2. Script}

\section{A.2.1 Consent}

$<<$ Information read aloud at the beginning of each session to all participants in the waiting area >>

Hello. Welcome to today's meeting. Thank you for arriving on time. My name is I am a representative from IPA. I am here to assist in this data collection exercise which is part of the research project being conducted with IPA and you are called to meet with one of us one-on-one.

Before calling you to meet with us one on one we would like to read a consent form that will tell you a little bit about the purpose of this meeting. Please pay attention and ask questions at any time.

\section{Consent}

You have been invited to this meeting because you are currently participating in a research project conducted by researchers from IFPRI, IPA, and the World Bank. This meeting is part of a research project being conducted with everyone who expressed interest in renting land with irrigation and/or in receiving credit for agricultural inputs with

your relationship with The events that take place during today's meeting will not affect you or anyone else makes. in any way. We will not tell or any of his staff what choices 
The objective of today's meeting is to collect some information for our research project. You are going to be asked to make choices in exchange for money. We are interested in studying the choices that you make. There are no right or wrong answers. We ask that you do what you think is best for you as the decisions that you make will determine the money that you can earn. We will provide you with detailed information about the decisions that you are asked to make once you agree to participate in this meeting.

You will be able to earn money for participating in today's meeting. A minimum sum of 3 GHC are guaranteed. The guaranteed amount is meant to cover any costs you may have needed to incur in order to be here today and will be paid to you individually regardless of the choices that you make.

Your participation in today's meeting is completely voluntary. You can decide to end your participation in this meeting at any time. You will earn the guaranteed 3 GHC regardless of whether or not you decide to end your participation in the meeting. If you choose not to participate in the meeting or end your participation at any time you will not be eligible to earn any additional money.

The choices that you make today will be confidential. We will not reveal to anyone outside our research team what choices you make.

If you end your participation in this meeting at any time we may keep a record of the decisions that you make up until that point in the meeting. Your decisions will not be revealed to anyone outside our research team even if you decide to end your participation in this meeting at any time.

We will give you the opportunity to ask questions and tell us whether you give consent to participate in the meeting when we call you to meet with us one on one.

Just so you know, the information I just read applies to you only if you were invited to participate in this meeting. Please do not wait around if you were not invited. We will not be able to accommodate you in a one on one interview if you were not invited ahead of time. Also know that we are not affiliated with any political organization. This has nothing to do with politics.

\section{Registration}

$<<$ Read to spouses together after their names and id numbers are registered $>>$

I read a consent form to everyone who was waiting to be interviewed. Did you hear all the information that was provided?

$<<$ If yes, proceed. If not, consent form was read again to participants $>>$

Do you have any questions about the information that was provided to you? Feel free to ask them now.

$<<$ Answer questions $>>$

If you consent to participate in this meeting, please give verbal consent now.

$<<$ If consent is given: >> As you have agreed to participate, I have recorded your names here on this roster and I am marking here that you have given consent.

If you have any other problems or questions, do not hesitate to contact our Project Manager using the contact information on this card. 
$<<$ If consent given, proceed with interview. Direct each spouse to an enumerator pair for the individual decision making part. Enumerator pairs need to rotate who elicits the decisions of the husband and wife. They should also rotate every other interview who elicits the joint decisions. >>

$<<$ If no consent given $>>$ If you would prefer not to participate in this meeting, you are free to go at this time.

$<<$ If consent is not given, direct each spouse to payment enumerator. They will receive their guaranteed individual fee of 3 GHC. Participants who do not provide consent cannot participate in the meeting. If one spouse gives consent and the other one does not, then both spouses will not be allowed to make decisions in exchange for money and will be paid the individual 3 GHC fee. >>

\section{A.2.2 Interview script used to elicit incentivized decisions}

Hello. My name is I am a representative from data collection exercise which is part of the research project being conducted with and am here to assist in this

Today's meeting will be divided in 3 tasks. In each task you will have to make one or more decisions in exchange for money. At the end of the meeting one of the 3 tasks will be randomly selected to count for payment. Which task counts for payment will be determined by the computer. We use a computer to determine which task is paid to ensure that everything is done in a fair and unbiased manner. Which task is paid will not be revealed to you or your $\$$ \{spouse $\}$ to ensure that the choices that you make are private.

Any additional money that you earn will be will be paid to you in cash and in private at the end of the meeting. It is up to you whether you decide to tell your $\$\{$ spouse $\}$ how much you earn or not. Even if you do choose to tell your $\$$ \{spouse \} how much you earned, there is no way that he/she will be able to know what decisions you made. This is because only one of the 3 tasks will be randomly chosen for payment, and one of these tasks is a lottery.

We will now proceed with task 1.

\section{Task 1}

Your task is to select a card from this set. The card that you select will determine the earnings that your $\$\{$ spouse will receive if this task is paid. Your $\$$ \{spouse\} will be asked to make a similar choice, and the card that he or she draws will determine the payment that you will receive.

These are the cards: $<<$ Show them $>>$. They have a value between 0 and $21 \mathrm{GHC}$.

Each card is associated with a unique value. We will not reveal to you the value of the card that you draw. Likewise, we will not reveal to your $\$\{$ spouse $\}$ the value of the card that your $\$\{$ spouse $\}$ draws.

For example:

- $\quad$ This card may have a value of $21 \mathrm{GHC}<<$ show the card $>>$

- $\quad$ This card may have a value of $20.5 \mathrm{GHC}<<$ show the card $>>$

- $\quad$ This card may have a value of $20 \mathrm{GHC}<<$ show the card $>>$

- $\quad$ This card may have a value of 19.5 GHC $<<$ show the card $>>$ 
- $\quad$ And so on.

Since all values between 0 and 21 are equally likely to be selected, you and your $\$\{$ spouse $\}$ can each receive any sum between 0 GHC and 21 GHC if this task is paid.

For example:

- $\quad$ You may both receive 0 GHC.

- $\quad$ You may both receive 0.5 GHC.

- $\quad$ You may both receive $1 \mathrm{GHC}$, and so on.

It is also possible that:

- $\quad$ You receive 0 GHC while your $\$$ spouse $\}$ receives 0.5 GHC

- $\quad$ You receive 0 GHC while your $\$$ \{spouse $\}$ receives 1 GHC.

- $\quad$ You receive 0 GHC while your $\$$ spouse $\}$ receives 1.5 GHC.

- $\quad$ You receive $0 \mathrm{GHC}$ while your $\$$ spouse $\}$ receives $21 \mathrm{GHC}$

- OR

- You receive 21 GHC while your $\$$ \{spouse $\}$ receives 0 GHC.

Any combination of values between 0 and $21 \mathrm{GHC}$ is thus possible.

Please select a card, by pointing to it. Please do not flip it or look at its letter value.

$<<$ Record choice, but do NOT show value to participant $>>$

Remember that this may be the task that is randomly selected for your payment. Therefore, when all tasks are completed, even if your $\$$ \{spouse knows how much you earn, he/she will still not know what decisions you have made in tasks 2 and 3.

For example, if a wife receives a high payment at the end, her husband cannot think this means that the wife mostly chose to keep money for herself. It could simply be the case that task 1 was chosen for payment and she got a high-value card draw. The same would apply to a husband, who receives a high payment in the end. The wife cannot think that the husband mostly chose to keep money for himself. It could simply be the case that task 1 was chosen for payment and he got a high value card draw.

We will now proceed with task 2.

\section{$\underline{\text { Task } 2}$}

In this task you will have to make 2 decisions. One of the decisions that you and your $\$\{$ spouse $\}$ make will be randomly selected to be paid if this task is paid. All the decisions that you and your $\$\{$ spouse $\}$ make in this task are equally likely to be paid.

$<<$ Decision 1: Pull out 10 GHC visual aid from booklet and have it ready for use $>>$

We would like to give your household $10 \mathrm{GHC}<<$ Hold up fake $10 \mathrm{GHC}>>$

Who would you choose to receive this money, yourself or your $\$\{$ spouse $\}$ ?

$<<$ Record choice $>>$ 
$<<$ Decision 2: Pull out 15 GHC visual aid from booklet and have it ready for use together with the 10 GHC visual aid $>>$

$<<$ If answer is respondent $>>$ What if instead we were offering to give your household 10 GHC if received by YOU $<<$ Hold up face 10 GHC $>>$ or 15 GHC if received by YOUR $\$$ \{spouse $<<$ Hold up fake 15 GHC bill $>>$. Would that change your decision about who you choose to receive it?

$<<$ Confirm $>>$ Just to confirm, you chose X for $<<$ you/your husband / your wife $>>$ instead of Y for $<<$ your husband/ your wife/you $>>$. Is that correct?

$<<$ If yes, record choice. If no, repeat explanation. $>>$

$<<$ If answer is spouse $>>$ What if instead we were offering to give your household 10 GHC if received by YOUR $\$\{$ SPOUSE $\}<<$ Hold up face 10 GHC $>>$ or 15 GHC if received by YOU $<<$ Hold up fake 15 GHC bill $>>$. Would that change your decision about who you choose to receive it?

$<<$ Confirm $>>$ Just to confirm, you chose $\mathrm{X}$ for $<<$ you / your $\$$ \{spouse $\}>>$ instead of $\mathrm{Y}$ for $<<$ your $\$\{$ spouse $\} /$ you $>>$. Is that correct?

$<<$ If yes, record choice. If no, repeat explanation. $>>$

We will now proceed with task 3.

$\underline{\text { Task } 3}$

In this task you and your $\$$ spouse $\}$ will make a total of 8 decisions. Each time you will have to decide how much money you would like to keep and how much you would like to allocate to another option. One of the 8 decisions that you and your $\$$ \{spouse\} make will be randomly selected to determine payments if this task is paid. All of the decisions are equally likely to be paid.

Do you have any questions? $<<$ Answer questions $>>$

We will now proceed with decision 1.

\section{Decision 1 - Individual allocation decision}

We would like to give 14 GHC to your household and would like to know how you would like divide this money between you and your $\$$ \{spouse . You can divide the money in 2 GHC increments.

For example, you can choose...

$<<$ Show choices on visual aid booklet. Start at the top for husband and at the bottom for wife. $>>$

- $\quad 14$ GHC for you and 0 GHC for your $\$$ spouse $\}$

- $\quad 12$ GHC for you and 2 GHC for your $\$$ spouse $\}$

- 10 GHC for you and 4 GHC for your $\$$ spouse $\}$

- $\quad$ And so on...

- $\quad$ You can also choose 0 GHC for you and 14 GHC for your $\$$ spouse $\}$ 
If you give your $\$$ spouse 2 2GHC, how much would you get? $<<$ Check understanding and repeat explanation if necessary $>>$

Remember, there are no right or wrong decisions. Any allocation decision that you make is acceptable and is private. Privacy is ensured by the fact that any possible allocation that you can make could also have resulted if task 1 was paid. You and your $\$$ \{spouse\} will not know which task was paid.

Do you have any questions before we proceed? $<<$ Answer questions $>>$

Now please tell me, if this decision is the only one paid, what decision you would like to make? Please point to it on the menu.

$<<$ Record decision $>>$

We will now proceed with decision 2.

$$
\text { Decision } 2 \text { (form A) - Individual investment decision, self }{ }^{1}
$$

We have 7 GHC to give YOU and would like to give you the opportunity to invest all, part, or none of the 7 GHC in account that multiplies your investment by 3 half of the time and by 0 half of the time. Whether the money you invest is multiplied by a factor of 3 will be determined by the flip of a coin. If the outcome is HEADS then your investment will be multiplied by 3. If it is TAILS you will lose your money. The flip of the coin will be done by the computer to ensure that everything is done in a fair an unbiased manner.

Your investment can be made in increments of $1 \mathrm{GHC}$. All earnings from this decision will be paid to YOU exclusively. $<<$ Show individual icon $>>$

These are your possible investment choices: $<<$ Show visual aid page $1>>$

- $\quad$ You could invest 0 GHC and keep all 7 GHC. Then YOU would get nothing from your investment decision.

- $\quad$ You could invest 1 GHC and keep 6 GHC. Then YOU would get 0 GHC from your investment decision if it the outcome of the coin flip is TAILS, and 3 if it is HEADS. This in addition to the money you kept.

- You could invest 2 GHC and keep 5 GHC. Then YOU would get 0 GHC from your investment decision if it the outcome of the coin flip is TAILS, and 6 GHC if it is HEADS. This in addition to the money you kept.

- $\quad$ And so on...

- You could also invest 7 GHC and keep 0 GHC. Then YOU would get 0 GHC from your investment if the outcome of the coin flip is TAILS, and 21 GHC if it is HEADS.

Adding what you keep and what you get from each possible investment opportunity we have the following table. $<<$ Show visual aid page $2>>$

It shows the total earnings associated with all possible investment scenarios.

- You could invest 0 GHC and keep all 7 GHC. Then YOU would earn 7 GHC if the outcome of the coin flip is TAILS or HEADS.

\footnotetext{
${ }^{1}$ Form B reversed the order of decision 2 and 3. Forms A and B were randomized across respondents.
} 
- You could invest 1 GHC and keep 6 GHC. Then YOU would earn 6 GHC if the outcome of the coin flip is TAILS, and 9 GHC if it is HEADS.

- You could invest 2 GHC and keep 5 GHC. Then YOU would earn 5 GHC if the outcome of the coin flip is TAILS and 11 GHC if it is HEADS.

- $\quad$ And so on...

- You could also invest all 7 GHC and keep 0 GHC. Then YOU would earn 0 GHC if the outcome of the coin flip is TAILS and 21 GHC if it is HEADS.

If you invest 2GHC, how much would you get if the outcome of the coin flip is TAILS? If the outcome of the coin flip is HEADS? << Check understanding and repeat explanation if necessary $>>$

If you invest 5GHC, how much would you get if the outcome of the coin flip is TAILS? If the outcome of the coin flip is HEADS? << Check understanding and repeat explanation if necessary $>>$

As I said before, all of the earnings from this decision would be paid to YOU. $<<$ Show individual icon $>>$

Do you have any questions? $<<$ Answer questions $>>$

Remember, there are no right or wrong decisions. Any amount that you want to invest is acceptable and is private. Privacy is ensured by the fact that any possible outcome of your decision could also have resulted if task 1 was paid. You and your $\$\{$ spouse $\}$ will not know which task is paid.

Now please tell me, if this decision is the only one paid, what amount, if any, would you like to invest? Please point to the choice on the menu.

$<<$ Record choice $>>$

\section{Decision 3 (form A) - Individual investment decision, household}

Now I am going to give you the same investment opportunity as before, but now all earnings from the decision will be equally split between YOU AND YOUR \$ SPOUSE.$<<$ Should household icon $>>$

We have 7 GHC to give to your household and would like to give you the opportunity to invest all, part, or none of the 7 GHC in account that multiplies your investment by 3 half of the time and by 0 half of the time.

The possible choices and associated returns are the same as before $<<$ Show visual aid page $1>>$

The total payoffs associated with each choice are also the same $<<$ Show visual aid page $2>>$

The only difference is that the earnings from this decision would be equally split between YOU AND YOUR \$ SPOUSE.$<<$ Show household icon $>>$

Remember, there are no right or wrong decisions. Any amount that you want to invest is acceptable and is private. Privacy is ensured by the fact that any possible outcome of your decision could also have resulted if task 1 was paid. You and your $\$$ \{spouse $\}$ will not know which task is paid.

Now please tell me, if this decision is the only one paid, what amount, if any, would you like to invest? Please point to the choice on the menu.

$<<$ Record choice $>>$ 
We will now proceed with decisions 4 and 5, which will be jointly made by you and your $\$\{$ spouse $\}$. Your $\$\{$ spouse will have made the same decisions that you have made but will NOT know the choices you have made.

Please wait / follow me.

$<<$ Send participant to the booth of the enumerator who will be eliciting the joint decisions, or wait for both spouses to come to you if you are eliciting the joint decisions. >>

\section{Decision 4 - Joint allocation decision}

We are now going to ask you to make the same allocation decision you did before. $<<$ Show visual aid $>>$

We have 14 GHC to give to your household and would like to know how you would like divide this money between the both of you. The division will be made in increments of 2 GHC.

Do you have any questions? $<<$ Answer questions $>>$

I am now going to give you some privacy so that you can make your decision. Here is the menu of possible choices. Please take it with you and consider how you would like to divide the money if this was the only decision paid. The decision that you make together will be private, we will not reveal it to anyone else.

$<<$ Leave spouses alone for a few minutes so that they can make a private choice and keep track of the time they take to reach a decision. $>>$

Please tell me, if this decision is the only one paid, what choice did you make? Please point to it on the menu.

$<<$ Record decision $>>$

\section{Decision 5 - Joint investment decision}

We are now going to ask you to make the same investment decision you did before. $<<$ Show visual aid $>>$

We have 7 GHC to give to YOUR HOUSEHOLD and would like to give you the opportunity to invest all, part, or none of the $7 \mathrm{GHC}$ in account that multiplies your investment by 3 half of the time and by 0 half of the time.

The possible choices and associated returns are the same as before $<<$ Show visual aid page $1>>$

The total payoffs associated with each choice are also the same $<<$ Show visual aid page $2>>$

The earnings from this decision would be equally split between YOU AND YOUR \$ SPOUSE $\}.<<$ Show household icon $>>$

Do you have any questions? $<<$ Answer questions $>>$

I am now going to give you some privacy so that you can make your decision. Here is the menu of possible choices. Please take it with you and consider how much you would like to invest if this decision is the only one paid. The decision that you make together will be private, we will not reveal it to anyone else. 
$<<$ Leave spouses alone for a few minutes so that they can make a private choice and keep track of the time they take to reach a decision. $>>$

Now please tell me, if this decision is the only one paid, what amount, if any, would you like to invest? Please point to the choice on the menu.

$<<$ Record decision $>>$

Thank you. I will now ask that you wait for a few minutes in $<<$ Indicate place $>>$ until we calculate the payment that each of you should receive. We are going to pay you separately and in private. You can leave once we pay you.

$<<$ Give payment enumerator the payment forms and inform registration desk that they can start eliciting the consent of a new set of respondents. $>>$

\section{$\underline{\text { Payment }}$}

$<<$ To be read once data from the decision forms has been entered into the tablet and the payment questionnaire for the respondent is pulled up $>>$

Ok. Please come with me.

$<<$ Take participant to a private setting $>>$

This is your 3 GHC show-up fee. $<<$ Pay participant the show up fee $>>$

These are your decision earnings $<<$ Pay participant his or her decision earnings $>>$.

We are giving them to you separately because we want to make sure that you can keep your choices private. You can put it away now. $<<$ Encourage participant to put away the money $>>$

Remember that all the choices you made today are private. Your $\$$ \{spouse \} does not know what individual choices you made or how much money you have earned. Likewise, you do not know what individual choices your $\$$ \{spouse $\}$ has made or how much money your $\$\{$ spouse $\}$ has earned. Your $\$\{$ spouse $\}$, just like you, may have received as little as $3 \mathrm{GHC}$ or as much as $24 \mathrm{GHC}$ (including the show-up fee) due to task 1.

Please sign this receipt.

$<<$ Receipt is kept by enumerator $>>$ 


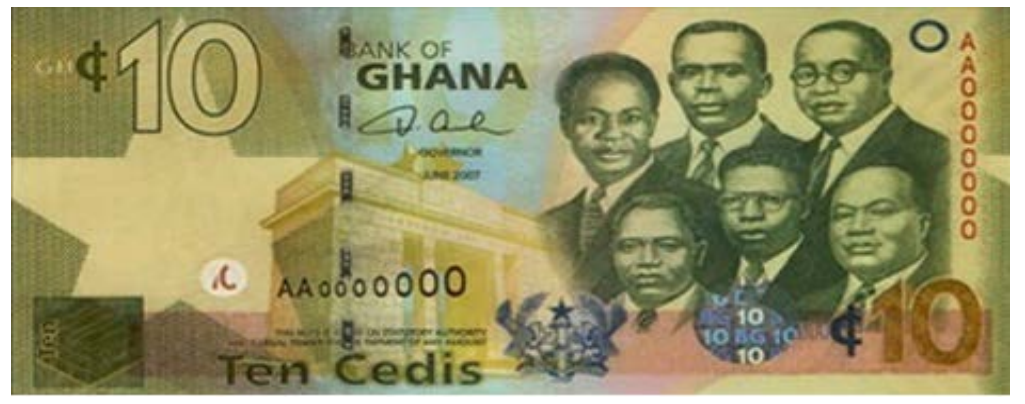

Image 2. Shown together with image 1 when eliciting decision 2 (A5 page)

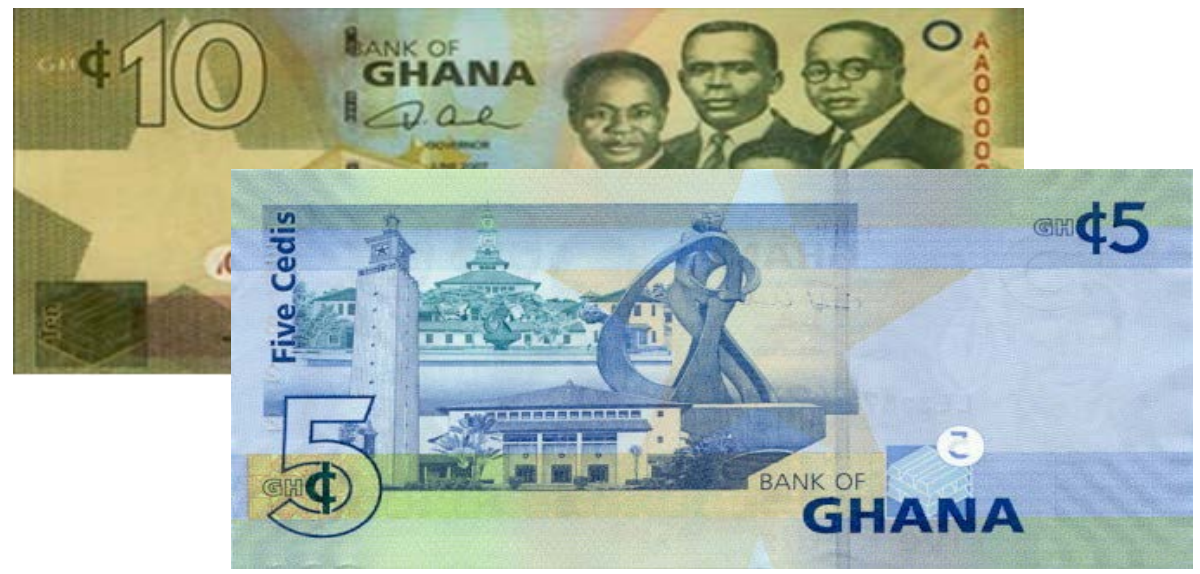


Shown to participants when eliciting private and joint dictator game decisions (fold-out menu) Dimensions: 8-3/4 X 15-1/4"

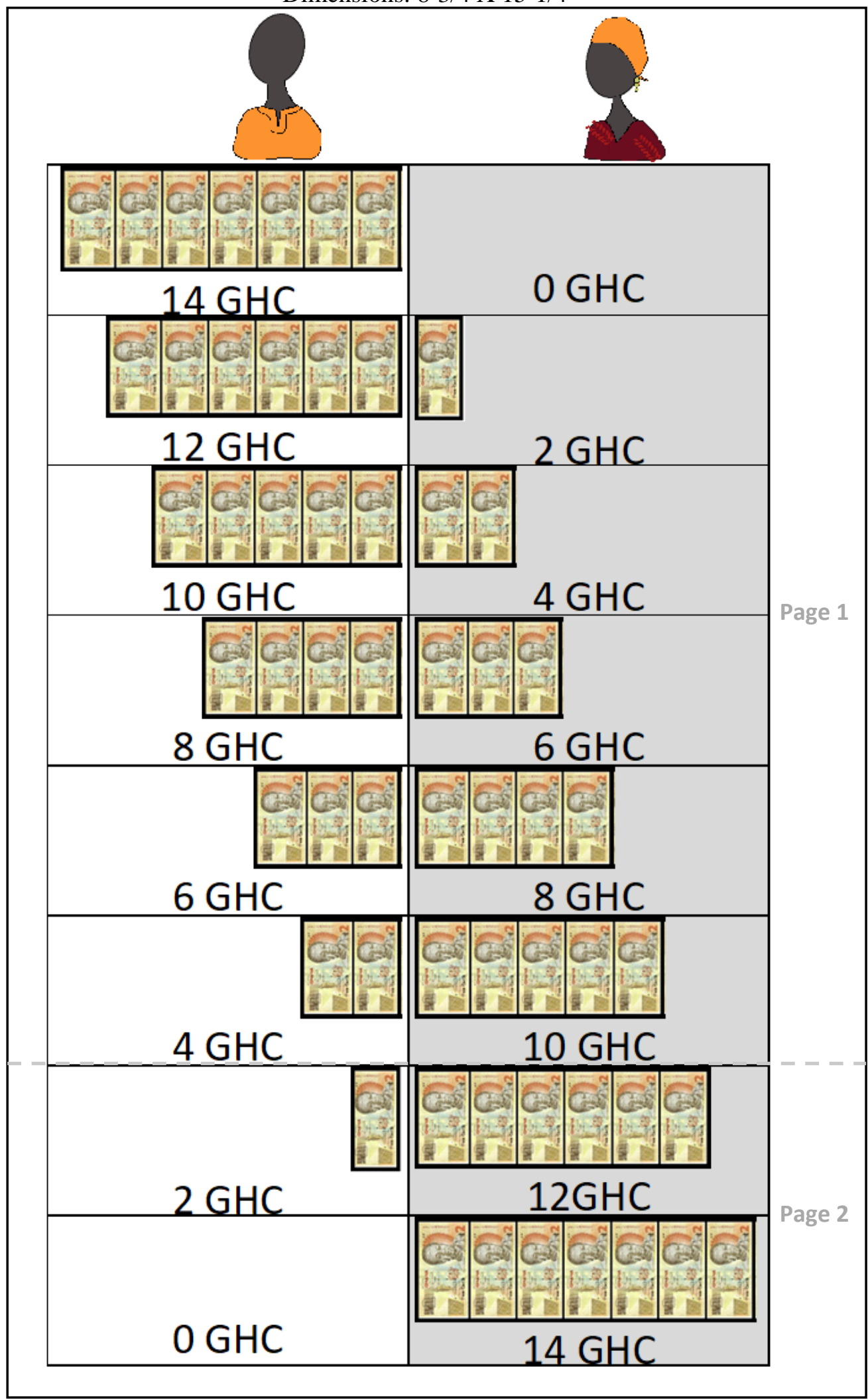


Visual aids. Investment decisions

Each image was printed on a separate A4 page.

Image 1. Individual icon shown to husband, when eliciting private decision for self

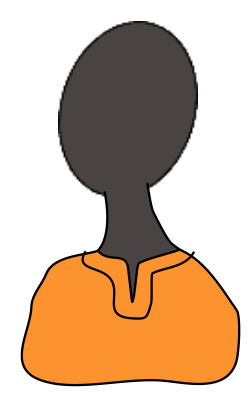

Image 1. Individual icon shown to wife, when eliciting private decision for self.

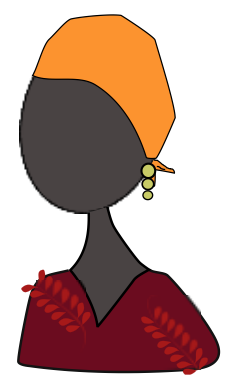

Image 1. Household icon shown to participants, when eliciting private and joint decisions for household

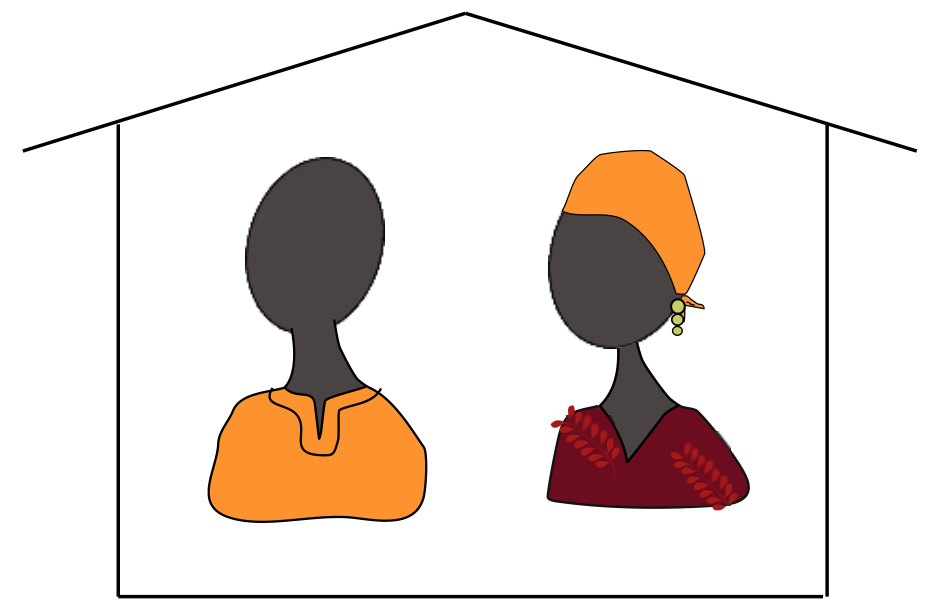




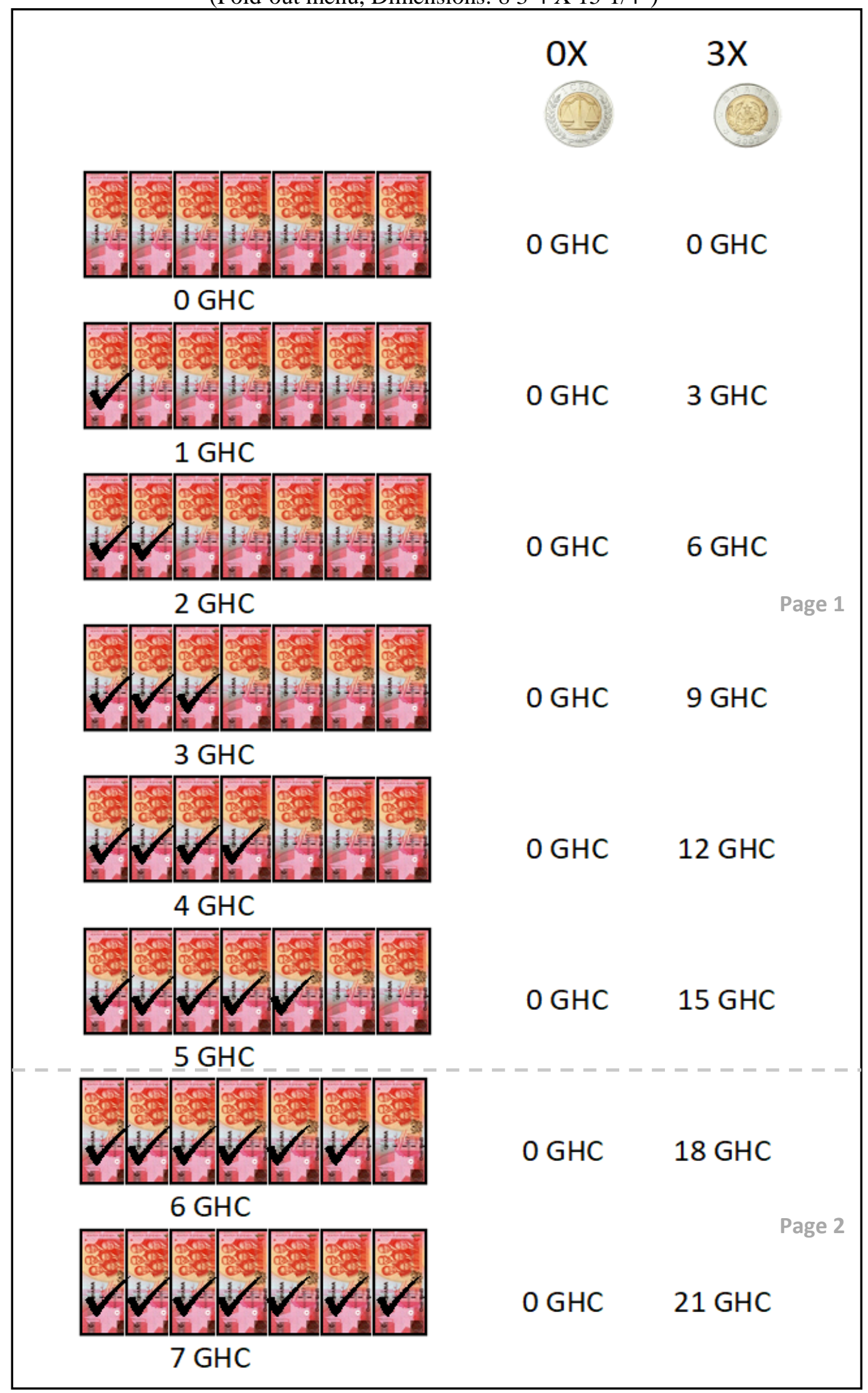

Note: Visual aid page 1 in the interview script provided in section A.2.2. 


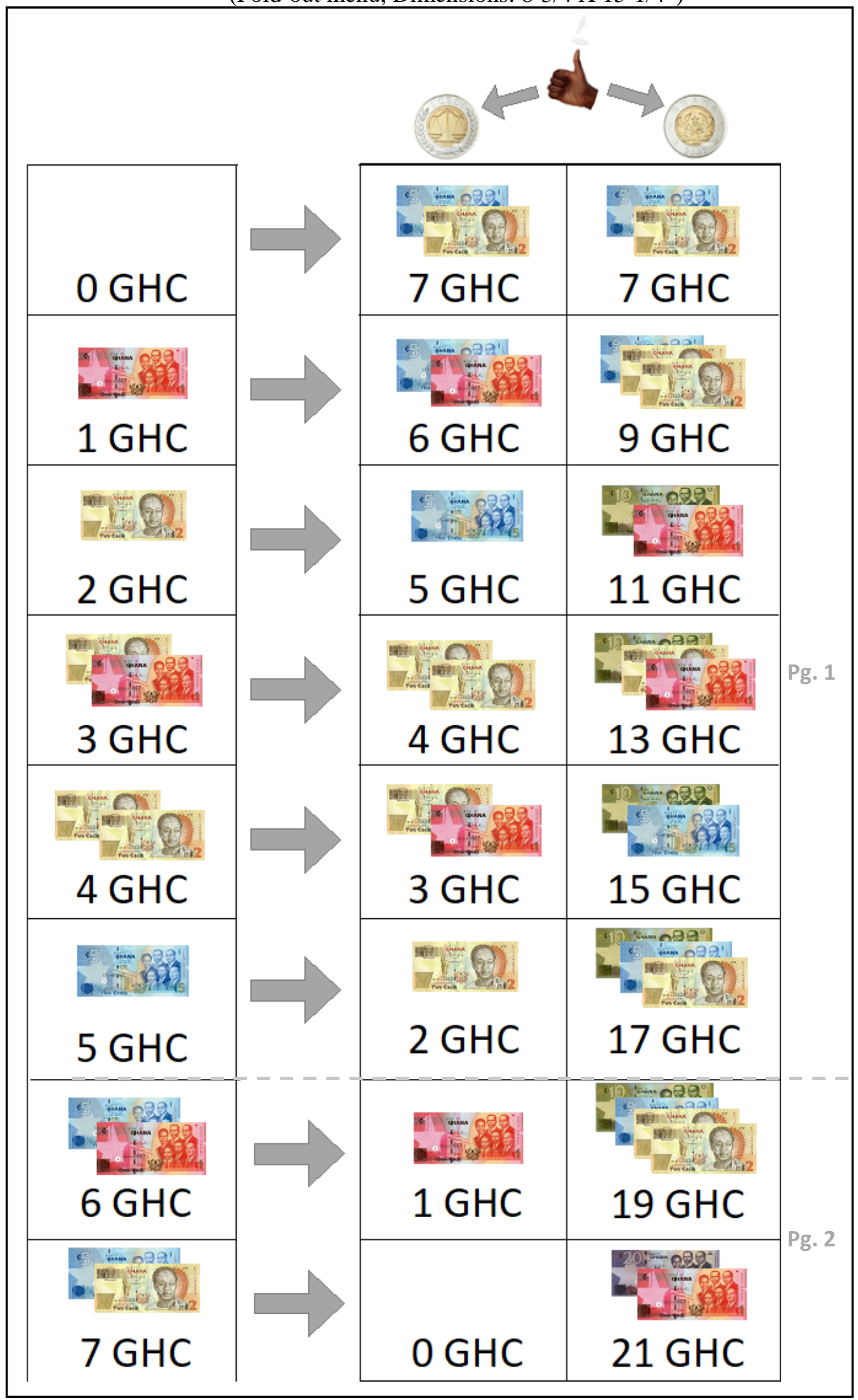

Note: Visual aid page 2 in the interview script provided in section A.2.2. 


\section{Appendix B. The Uganda Experiment}

\section{B1. Experimental procedures}

All spouses who were part of the baseline sample of the randomized control trial conducted by Ambler, Jones, O'Sullivan (2019) were given the opportunity to participate in the lab-in-the-field experiment. Unlike in our Ghana sample, the lab-in-the-field experiment was conducted at each couple's home, by one enumerator, together with a larger household survey about farm and family practices. Couples were recruited from lists of farmers associated with a local sugar company. Participants were first determined to be eligible and willing to participate and then proceeded with the lab-in-the-field experiment and baseline survey. ${ }^{1}$ Attempts were made to schedule interviews 2-3 days in advance, but because locating many of the potential participants was difficult, ultimately most interviews occurred when the participants were located and available. Participants were informed that they would be able to earn money and were guaranteed a minimum payment of 1,000 UGX (\$0.30USD).

Interviews for the lab-in-the-field experiment took place sequentially, before the larger household survey was administered. Procedures were as follows. First, both spouses were given some general information and we elicited consent to participate in the study. Then the spouse that was readily available and the couple agreed should go first was interviewed in private. After the first spouse made all private incentivized decisions, the second spouse was interviewed in private. Once private incentivized decisions were elicited from both spouses, the couple was brought together to make joint decisions. After making all incentivized decisions, the household survey was administered. This survey included private and joint interview modules. Participants were paid for their incentivized decisions after their involvement in the household survey concluded. It took approximately 30 minutes for the incentivized decisions to be elicited. However, the lab-in-the-field experiment and the household survey took approximately 3 hours.

\section{B.2. Script}

\section{B2.1 Consent}

$<<$ Read to spouses together $>>$

This household has been identified as eligible to participate in the Farm \& Family Balance Study, which is being conducted by the International Food Policy Research Institute (IFPRI), an international organization dedicated to research into the elimination of poverty and hunger in collaboration with the World Bank's Gender Innovation Lab (GIL). The objective of this study is to learn more about how households manage their farms and their income. If you choose to participate in this study, we would like to interview both of you today to learn more about these topics.

We will also first ask you to make choices in exchange for money. We are interested in studying the choices that you make. You will be able to earn money for participating and a minimum sum of 1,000 UGX is guaranteed for each of you.

We would like to conduct these interviews both together then separately and each in private, as we would like each of you to answer on your own without any influence from each other. Each interview should take approximately 1 hour and a half.

\footnotetext{
${ }^{1}$ Eligibility criteria were determined for the randomized control trial that followed. These criteria included active sugarcane farming, being married, having an active eligible sugarcane block, and having no outstanding loans against sugarcane blocks.
} 
Some households who choose to participate in this study may be invited to a training later this year and/or may receive additional household visits in the future. This will not be the case for all households participating in the study and the selection will be by lottery. Nothing you say today will have any impact on your selection for other study activities. Households selected for these additional activities may benefit from that participation. Even if you are not selected for additional activities, your participation will help us to learn valuable things about your community that may result in improved programs and services in your area in the future. All participants in the study will be requested to complete another interview in about 18 months' time, which will also last about 1 hour and a half.

Your participation in this study is your choice. If you do choose to participate you can change your mind at any time. If any question we ask during the interview makes you uncomfortable, you can choose not to answer it. There are no penalties or benefits to you that will be affected by your choices regarding participation. Your choice to participate or not will not affect your relationship with your community.

All your information and any answers to interview questions will be kept strictly confidential. Only the research team at IFPRI and at the World Bank will have access to this information and it will not be shared with any other entity. Your answers will be associated only with a study ID number and not with your name. Only data that does not contain your name will continue to exist after the study is finished.

Do you have any questions at this time?

Do you agree to participate in this study?

If you have any questions, concerns, or complaints during the study, you are free to contact the individuals shown below.

$<<$ Provide contact information $>>$

Do you have any questions at this time?

$<<$ Ask to male respondent: >> Do you agree to participate in this study?

$<<$ Ask to female respondent: $>>$ Do you agree to participate in this study?

$<<$ When BOTH respondents have given CONSENT, continue to next screen. If either respondent does NOT consent, STOP the interview. >>

\section{B.2.2 Interview script used to elicit incentivized decisions}

$<<$ Read to spouses together $>>$

I want to ask you to make some decisions that will determine how much money each of you will earn. Based on your decisions, you could earn any amount between 0 and $\$\{Z\}$ UGX. ${ }^{2}$ In addition to what you earn from your decisions, you will also receive 1,000 UGX as a thank you for participating, but each of you may earn as much as $\$\{Z\}$ UGX.

Before we begin I want to make sure that you understand a few important points.

${ }^{2} Z$ can acquire one of two values in the study, either 14,000 UGX or 28,000 UGX. Which value applies depends on the value of Y randomly assigned to the household in Tasks $3 \& 4$. 
1. There are no right or wrong answers. We ask that you do what you think is best for you because the decisions that you make will determine the money that you earn.

2. The decisions you make will be completely confidential. No one besides the research team will know what you decided. Each of you will not know what decisions your spouse has made.

3. You will be paid your earnings in private, separately from your spouse. It is up to you whether you decide to let him/her know how much you earned. Even if you do choose to tell your spouse how much you have earned, there will be no way for him/her to know what decisions you made. This is because each of you will make several different decisions, but no one will know which decisions are randomly chosen to be paid.

4. Participation in the decision-making part of this interview is completely voluntary. If you do not wish to participate you can take the 1,000 UGX but you will not earn anything additional.

If you choose to participate, I will ask you to complete 4 tasks. In each task you will have to make one or more decisions in exchange for money. After we finish, one of the 4 tasks will be randomly selected to count for payment. Which task counts for payment will be determined by the computer. We use a computer to determine which task is paid to ensure that everything is done in a fair and unbiased manner. Which task is paid will not be revealed to either of you to ensure that the choices that you make are private.

Any additional money that you earn will be paid to you in cash and in private later today. It is up to you whether you decide to tell your spouse how much you earn or not. Even if you do choose to tell your spouse how much you earned, there is no way that he/she will be able to know what decisions you made. This is because only one of the 4 tasks will be randomly chosen for payment, and one of these tasks is a lottery.

$<<$ Enter spouse readily available for interview $>>$

$<<$ To spouse interviewed first:>> At this time I would like to speak privately with you.

$<<$ To spouse not interviewed first $>>$ Please excuse us for a short while and I will speak with you privately afterward.

$<<$ Enumerator takes respondent to a private place where the decisions can be administered. $>>$

\section{Task 1}

Your task is to select a card from this set. The card that you select will determine the earnings that you could receive if this task is paid. Your $\$$ \{spouse $\$$ \{will be asked $\backslash$ has been asked to make a similar choice, and the card that he/she $\$$ \{draws $\backslash$ drew will determine \} the payment that he/she could receive.

These are the cards: << Show them and allow respondent to hold if they ask. $>>$ They have a value between 0 and $\$\{Z\}$ UGX.

Each card is associated with a specific value. We will not reveal to you the value of the card that you draw. Likewise, we will not reveal to your $\$\{$ spouse $\}$ the value of the card that your $\$\{$ spouse $\}$ draws.

For example:

- Any card you choose may have a value of $\$\{Z\}$, such as this one or this one. $<<$ Show the cards $>>$

- Also, any card you choose may have a value of $\$\{Z 1\}$, or $\$\{Z 2\}$ or $\$\{Z 3\}$ and so on.

- Any card could also be a lower number, or even zero.

The letter on the card does not indicate whether the value will be high or low. 
Since all values between 0 and $\$\{Z\}$ are possible to be selected, you could receive any sum between 0 and $\$\{Z\}$ if this task is paid. Your $\$$ \{spouse $\}$ could also receive any value between 0 and $\$\{Z\}$ if this task is paid. You could both receive the same value or very different values, since it is all up to chance.

Please select a card, by pointing to it.

$<<$ Record choice $>>$

Remember that this may be the task that is randomly selected for your payment. Therefore, when all tasks are completed, even if your $\$$ \{spouse $\}$ knows how much you earn, $\$\{$ helshe will still not know what decisions you have made in the other tasks.

You are now going to be asked to make some decisions that affect the money that you and your $\$$ \{spouse receive. These decisions will be private. For example, if a wife receives a high payment at the end, her husband cannot think this means that the wife mostly chose to keep money for herself. It could simply be the case that task 1 was chosen for payment and she got a high-value card draw. The same would apply to a husband, who receives a high payment in the end. The wife cannot think that the husband mostly chose to keep money for himself. It could simply be the case that task 1 was chosen for payment and he got a high value card draw.

We will now proceed with task 2.

$<<$ You may now put the lottery cards away. $>>$

\section{Task 2}

In this task you will have to make 2 decisions. One of the decisions that you and your $\$\{$ spouse $\}$ make will be randomly selected to be paid if this task is paid. All the decisions that you and your $\$$ \{spouse $\}$ make in this task are equally likely to be paid.

$<<$ Decision 2: Pull out 10,000 UGX from visual aid booklet and have it ready for use $>>$

We would like to give your household 10,000 UGX. $<<$ Point to \$10,000 UGX. $>>$

Who would you choose to receive this money, yourself or your $\$$ spouse $\}$ ?

$<<$ Record choice $>>$

$<<$ Decision 2: If answer to Q1 was 'Myself' .>>

$<<$ Prepare Decision 2 visual aids from booklet and have them ready for use. $>>$

What if instead we were offering to give your household $\$ 10,000$ if received by YOU. $<<$ Point to 10,000 UGX $>>$ or 15,000 UGX if received by your $\$$ \{spouse $\}.<<$ Point to 10,000 \& 15,000 UGX bills. $>>$ Would that change your decision about who you choose to receive it?

To be clear, you can receive 10,000 UGX yourself, OR your $\$$ \{spouse can receive 15,000 UGX, but only one of you will receive the money.

Would you choose to receive 10,000 UGX yourself or have your $\$$ \{spouse $\}$ receive 15,000 UGX? 
$<<$ Confirm $>>$ Just to confirm, you chose $\$\{$ choice $\}$ for $\$$ \{yourself / your spouse $\}$ instead of $\$$ \{not choice $\}$ for $\$\{$ your spouse / yourself $\}$. Is that correct?

$<<$ If yes, record choice. If no, repeat explanation. $>>$

$<<$ Decision 2: If answer to Q1 was 'My spouse'. >>

$<<$ Prepare Decision 2 visual aids from booklet and have them ready for use .>>

What if instead we were offering to give your household 10,000 UGX if received by your $\$$ spouse $\}<<$ Point to 10,000 UGX $>>$ or 15,000 UGX if received by you. $<<$ Point to $10,000 \& 15,000$ UGX bills. $>>$ Would that change your decision about who you choose to receive it?

To be clear, your $\$$ spouse can receive 10,000 UGX, OR you can receive 15,000 UGX, but only one of you will receive the money.

Would you choose to have your $\$$ \{spouse \} receive 10,000 UGX or receive 15,000 yourself?

$<<$ Confirm $>>$ Just to confirm, you chose $\$\{$ choice $\}$ for $\$$ \{yourself / your spouse $\}$ instead of $\$$ \{not choice $\}$ for $\$\{$ your spouse / yourself\}. Is that correct?

$<<$ If yes, select response. If no, repeat explanation. $>>$

We will now proceed with task $3 .<<$ Flip the visual aid booklet page to prepare for Task 3. You should see "Tasks 3 and 4" written. >>

\section{$\underline{\text { Task } 3}$}

In this task you will make one decision. If this task is paid either the decision made by you or the decision made by your $\$$ \{spouse \} will be randomly selected to be paid. Both the decision made by you and the one made by your $\$$ \{spouse $\}$ in this task are equally likely to be paid.

We would like to give $\$\{Y\}$ UGX to your household and would like to know how you would like to divide this money between you and your $\$\{$ spouse $\}$. You can divide the money in $\$\{Y / 7\}$ UGX increments. ${ }^{3}$

$<<$ Turn page to show visual aid booklets. Point to the image of the man and the woman. $>>$

This picture shows how you can divide the money. At the top are pictures representing you and your $\$\{$ spouse $\}$. << Indicate on visual aid. $>>$ Each row is one option that you can choose. For each option the money you would keep is shown on this side and the money your $\$$ \{spouse \} would keep is shown on this side.

For example, you can choose...

$<<$ Show choices on visual aid booklet. Start at the bottom if speaking with wife. Start at the top if speaking with husband $>>$

\footnotetext{
${ }^{3} Y=14,000$ for $75 \%$ of the sample, who makes choices in 2,000 UGX increments. $Y=28,000$ UGX for $25 \%$ of the sample who make choices in 4,000 UGX increments.
} 
- $\quad \$\{Y\}$ for you and 0 for your $\$\{$ spouse $\}$

- $\quad \$\{Y-Y / 7\}$ for you and $\$\{Y / 7\}$ for your $\$$ spouse $\}$

- $\quad \$\{Y-2 * Y / 7)\}$ for you and $\$\{2 * Y / 7)\}$ for your $\$\{$ spouse $\}$

- And so on...

- You can also choose 0 for you and $\$\{Y\}$ for your $\$\{$ spouse $\}$.

If you give your $\$\{$ spouse $\}\{Y / 7\}$, how much would you get? $<<$ If correct, say "That's correct". If not correct, repeat explanation starting with "We would like to give..." >>

Remember, there are no right or wrong decisions. Any allocation decision that you make is acceptable and is private. Privacy is ensured by the fact that any possible allocation that you can make could also have resulted if task 1 was paid. You and your \$ \{spouse\} will not know which task was paid.

Do you have any questions before we proceed? $<<$ Answer questions $>>$

Now please tell me, if this decision is the only one paid, what decision you would like to make? $<<$ Please tell me or point to it on the menu. >>

$<<$ Record decision $>>$

We will now pause to ask the same questions of your spouse and return to you for the last task in a few minutes. Please wait here while I call your spouse to join us.

$<<$ Now call or find second person. When second person has joined, say to the first person: $>>$ Now your spouse will complete the same tasks that you have done but will NOT know the choices you have made. Please excuse us while I speak privately with your spouse. Thank you for your patience.

$<<$ Repeat Tasks 1-3 with second person $>>$

$<<$ To second person, after he/she makes decisions in Tasks 1-3 $>>$ We will now proceed with Task 4, which will be a decision made jointly by you and your spouse. Your spouse has completed the same tasks that you done but will NOT know the choices you have made. Please wait here while I ask your spouse to join us.'

\section{$\underline{\text { Task } 4}$}

We are now going to ask you to make the same allocation decision you did before. $<<$ Re-open visual aid book to the last page you were on (correct set for page Task 3 and 4). >>

We have $\$\{Y\}$ UGX to give to your household and would like to know how you would like to divide this money between the both of you. The division will be made in increments of $\$\{Y / 7\}$ UGX.

Do you have any questions? $<<$ Answer questions. Remove page from visual aid booklet and give to respondents. >>

I am now going to give you some privacy so that you can make your decision. Here is the menu of possible choices. Please keep it with you and consider how you would like to divide the money if this was the only decision paid. The decision that you make together will be private, we will not reveal it to anyone else.

$<<$ Leave spouses alone for a few minutes so that they can make a private choice and keep track of the time they take to reach a decision. $>>$ 
Please tell me, if this decision is the only one paid, what choice did you make?

$<<$ Record time taken to reach decision and who announced the decision $>>$

$<<$ Say to the person who did not announce the decision: $>>$ Do you agree with this decision?

$<<$ If no: >> In order for this to be a joint decision, you will both have to agree on how to divide the money. I will leave you for a few more minutes so that you can reach an agreement.

$<<$ Record decision $>>$

Thank you for completing this decision-making exercise. We will now proceed with the interview. I will ask you to stay together here to answer together some questions about your household.

$<<$ Close visual aid booklet and put it aside. Then proceed with household survey >>

\section{$\underline{\text { Payment }}$}

$<<$ Done in private with each respondent after they have finished answering all household survey questions $>>$

$<<$ You are about to pay the respondent who completed their individual interview $\$\{$ first/second $\}$. This is the $\$$ spouse interviewed first/second $\}$. $>>$

$<<$ Find a PRIVATE place away from view of the respondent to put the money in the envelope and fill in the paper receipt with the respondent's payment information. Then go back to respondent. >>

Thank you for answering all my questions. Now that we are finished together, I would like to give you the money you earned in the decision-making exercise at the beginning of our meeting.

Remember that you and your spouse completed 4 tasks each, and only one of those tasks has been selected to be paid. The selection of which task to pay was made by the computer. I have no control over which task was selected. In addition, if the first task was selected for payment, I have no control over the value of the card that you chose, that value is also determined by the computer. The final outcome for you resulted in a payment of $\$\{\mathrm{P}\}$ shillings. Please sign this imprest form to confirm that you are receiving this amount.

$<<$ Give the filled imprest form for signature. After signature, collect imprest form and give the envelope with cash. $>>$

Thank you for your time today.

\section{B3. Visual aids}

The visual aid material uses the same format as in the Ghana Experiment and is therefore not shown in this appendix. 


\section{Appendix C: Index Construction}

The survey measures examined in Tables 4 and 5 of this paper are analyzed through the creation of standardized indices to create a summary measure for each category of outcome. We use a method described by Kling, Liebman, and Katz (2007) to construct these measures. The procedure is as follows. Each component variable is standardized by subtracting its mean and dividing by its standard deviation. Then these components are summed, and this summed variable is again standardized by subtracting its mean and dividing by its standard deviation. The component variables and the categories are described in Appendix Table 4 for Ghana and in Appendix Table 5 for Uganda.

In addition to this standardization we implement a technique to create question-level indices for categorical variables as described in Heath, Hidrobo, and Roy (2018) and Roy et al. (2019). This method maintains the full variation in these variables without treating them as continuous. The method is as follows. Considering a variable with $n$ response options, we create $n-1$ dummy variables. For example, the decision-making questions in both countries are coded as "Wife has no say," "Wife has less than equal say," or "Wife has equal or more say." From these three categories we create two binary variables: "Wife has less than equal say or more" and "Wife has equal or more say." We then standardize each of these variables, take their average, and then standardize again. As such, cases where women have more decision-making power will have higher values. Each of these question-level indices is then used as a component of the category indices described in the previous paragraph. The categorical variables for which we use this method are preference

agreement and decision-making variables in Ghana and marital quality and decision-making variables in Uganda. 


\section{ALL IFPRI DISCUSSION PAPERS}

All discussion papers are available here

They can be downloaded free of charge

INTERNATIONAL FOOD POLICY RESEARCH INSTITUTE

www.ifpri.org

\section{IFPRI HEADQUARTERS}

1201 Eye Street, NW

Washington, DC 20005 USA

Tel.: +1-202-862-5600

Fax: +1-202-862-5606

Email: ifpri@cgiar.org 


\section{University Library}

\section{- M M I E E R VA A gateway to Melbourne's research publications}

Minerva Access is the Institutional Repository of The University of Melbourne

Author/s:

Ambler, K;Jones, K;Recalde, M

Title:

Measurement of Intra-household Resource Control: Exploring the Validity of Experimental Measures

Date:

2020-12-01

Citation:

Ambler, K., Jones, K. \& Recalde, M. (2020). Measurement of Intra-household Resource Control: Exploring the Validity of Experimental Measures. International Food Policy Research Institute.

Persistent Link:

http://hdl.handle.net/11343/259680 